Arqueología y Sociedad,

$N^{o} 18,2007$

\title{
Dinámica y desarrollo de un centro ceremonial andino. El caso de Cahuachi
}

Aïcha Bachir Bacha*

\begin{abstract}
Resumen
En la costa sur del Perú, el celebre sitio de Cahuachi (200 a.C.- 450 d.C.), el más vasto asentamiento de los antiguos Nasca, es tradicionalmente interpretado o como una capital que abrigaba una importante población, o al contrario como un centro exclusivamente ceremonial y de peregrinaje. Recientemente, el análisis de la cultura material permitió constatar la presencia de sectores residenciales al interior de los templos. Otros vestigios arqueológicos descubiertos particularmente en las zonas periféricas de los grandes monumentos, testimonian restos de ocupación domestica permanente. La organización arquitectónica del centro ceremonial tiende hacia una constitución de espacios cerrados y reservados que van en contra de una estructura urbana. Estos indicios invitan a cambiar la percepción establecida sobre la función del sitio.
\end{abstract}

Palabras claves

Perú, Costa sur, Nasca, Cahuachi, centro ceremonial, arquitectura, hábitat, cerámica, ofrendas.

\begin{abstract}
On the southern coast of Peru, the famous site of Cahuachi, the greatest establishment of the ancient Nasca, is traditionally interpreted as either hosting an important population or an exclusive ceremonial centre and a pilgrimage destination. Recently, analysis of cultural material reveal the existence of residential sections in the interior of the temples. Archaeological remains, in particular those excavated on periphery of the great monuments show proofs of permanent domestic life. The architectural organization of the ceremonial center tends toward enclosed and isolated spaces, far from the idea of an urban form. These elements pull us to change our mind about the function of this site.

$\mathrm{n}$ the southern coast of Peru, the famous site of Cahuachi, the greatest establishment of the ancient Nasca, is traditionally interpreted as either hosting an important population or an exclusive ceremonial centre and a pilgrimage destination. Recently, analysis of cultural material reveal the existence of residential sections in the interior of the temples. Archaeological remains, in particular those excavated on periphery of the great monuments show proofs of permanent domestic life. The architectural organization of the ceremonial center tends toward enclosed and isolated spaces, far from the idea of an urban form. These elements pull us to change our mind about the function of this site.
\end{abstract}

Keywords

South Coast, Nasca, Cahuachi, ceremonial center, architecture, habitat, ceramic, offerings.

* Ecole des Hautes Etudes en Sciences Sociales, Centre de recherche sur l'Amérique préhispanique, 10, Monsieur lePrince,75006Paris, bacha@ehess.fr 
El centro ceremonial de Cahuachi se desarrolló durante el periodo Nasca temprano (50 a. C. -450 d.C.). Sus inicios, sin embargo, se remontan alrededor del 200 a.C. (Nasca inicial). Cahuachi se encuentra a una altitud de 360 m.s.n.m., a 42 km. del Océano Pacifico y a $18 \mathrm{~km}$. al oeste de la ciudad de Nazca en el depar- tamento de Ica (Fig.1). El sitio se ubica en la margen izquierda del río Nazca, y por su frente norte esta bordeado por un bosque de huarangos (Prosopis pallida). Las pampas de San José y de Atarco, marcadas por los celebres geoglifos rodean el sitio por el norte y el sur. Las excavaciones arqueológicas y la fotografía aérea permiten

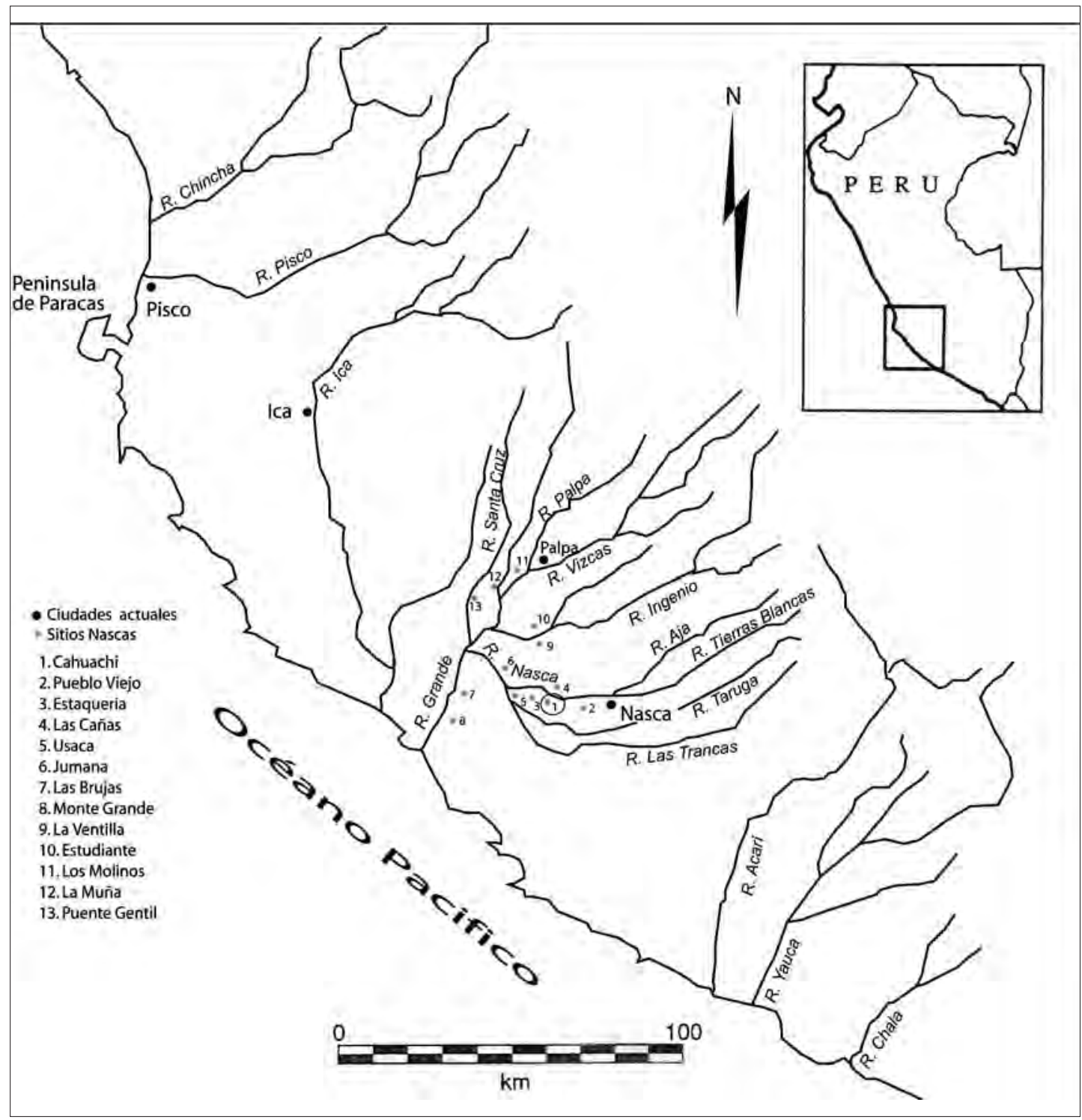

Figura 1. Ubicación de Cahuachi y otros sitios Nasca en la costa sur del Perú. 
distinguir una serie de plataformas y pirámides que se confunden con el relieve desértico sembrado de colinas. Hoy en día inhabitado, el sitio se extiende sobre $24 \mathrm{~km}^{2}$. Los monumentos de Cahuachi parecen pequeñas colinas pero en realidad se trata de edificios cubiertos por la arena eólica y por una capa de sedimentos de origen aluvial. Sobre el sitio, se observan algunos muros expuestos en la superficie.

La fotografía aérea da una buena visión del sitio. Se pueden distinguir tres sectores: uno oriental, uno central y uno occidental. Los edificios más importantes se concentran en la zona central (Fig. 2). Como regla general, los montículos y las plataformas se orientan hacia el norte, hacia el rió, aun si el eje de ciertos monumentos está ligeramente desviado hacia el este. Las últimas excavaciones en la Gran Pirámide han develado plataformas ascendentes con orientación norte-sur e igualmente una gran escalera que conduce hacia una estructura en forma de $U$, situada en la cima de la colina, la cual se orienta al este, en dirección a la gran duna de Cerro Blanco ${ }^{1}$ (Fig. 3).

La zona central comporta cuatro grandes conjuntos de edificios. Al sur, la Gran Pirámide (Y8) y el Gran Templo (Y5), al nor-este, El Templo del Escalonado (Y2) y los montículos 1 y $2(\mathrm{Y} 1)^{2}$. Este conjunto de edificios esta circundado por muros perimétricos. Hacia el este del montículo 1, las construcciones continúan hasta la Hacienda Cahuachi. El sector occidental presenta otro grupo de monumentos delimitados igualmente por muros perimétricos.

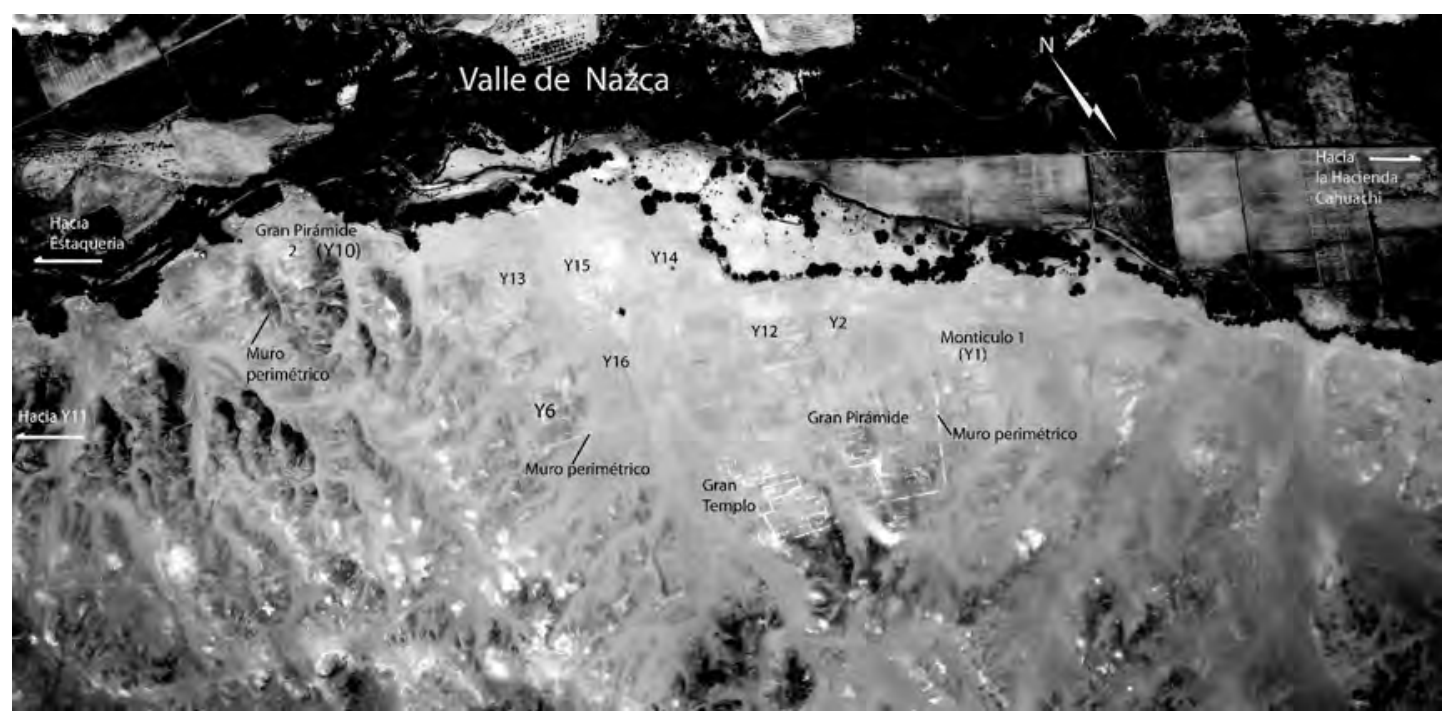

Figura. 2. Fotografía aérea del sitio de Cahuachi (foto del Instituto Geográfico Militar del Perú, 1955).

\footnotetext{
A propósito de esta huaca, una gran duna de 2000 m.s.n.m., se ha escrito: "En Cajamarca de La Nasca me mostraron un cerro grande de arena, que fue principal adoratorio o guaca de los antiguos. Preguntando yo qué divinidad hallaban allí, me respondieron, que aquella maravilla de ser un cerro altísimo de arena en medio de otros muchos todos de peña. Y la verdad era cosa maravillosa pensar como se puso tan gran pico de arena en medio de montes espesísimos de piedra." (Acosta [1590] 1962 : 224). Alberto Rossel Castro (1977) da cuenta de la importancia religiosa de Cerro Blanco entre las poblaciones contemporáneas de Nazca y Johan Reinhard (1997) lo asocia a los líneas de Nasca.

2 Para designar los diferentes sectores de Cahuachi utilizo la nomenclatura establecida por el CISRAP.
} 


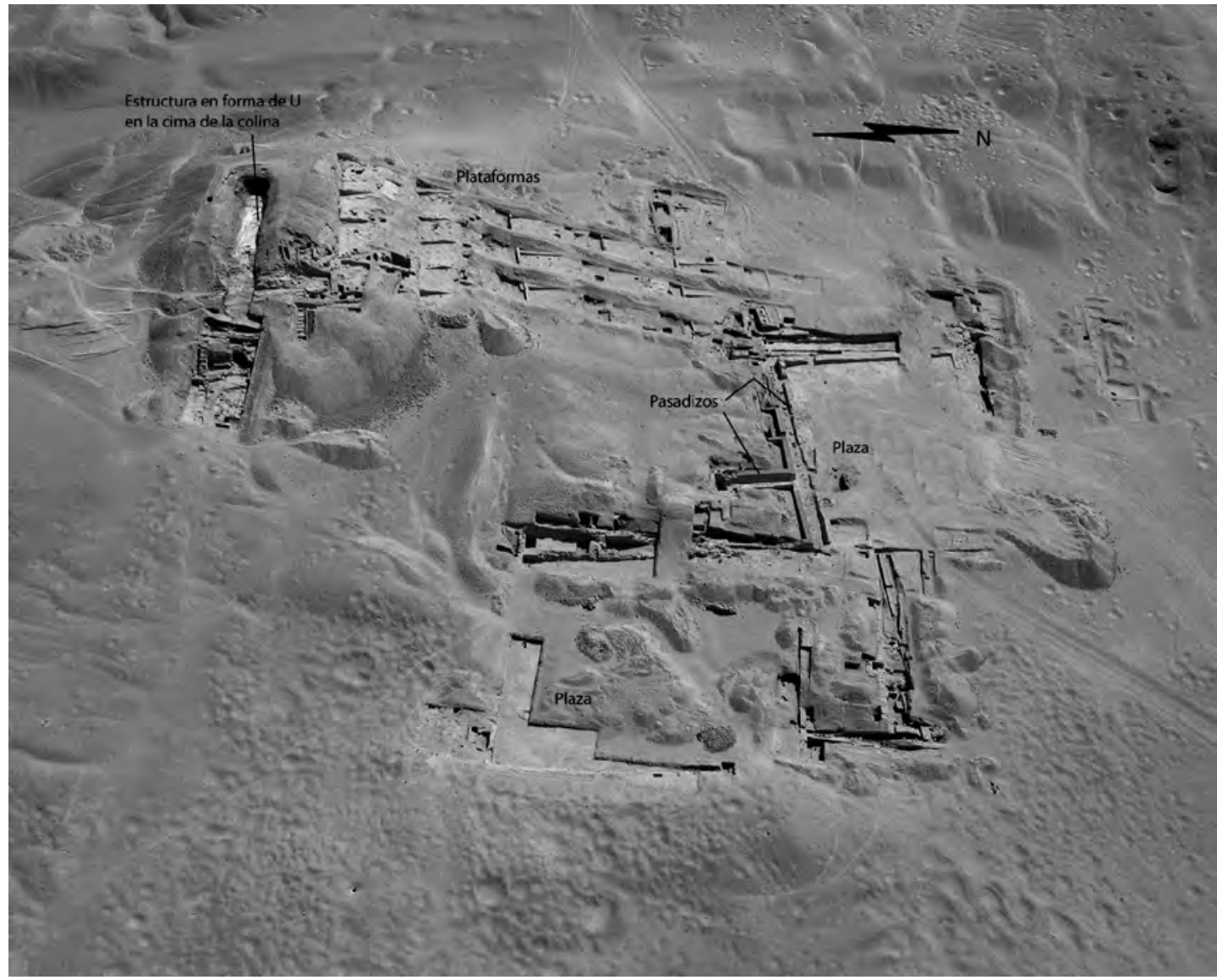

Figura 3. Fotografía aérea de las excavaciones en la Gran Pirámide, con la estructura en forma de U en la cima de la colina (excavaciones CISRAP, foto O. Bendezu, 2004).

Continuando al oeste de estas estructuras, se erige la Gran Pirámide 2, (Y10) la que esta rodeada por dos porciones de un muro perimétrico. A partir de este sector y dirigiéndose al sitio de Estaqueria, las construcciones se vuelven poco frecuentes y menos imponentes.

\section{Antecedentes y problemática}

La amplitud del sitio de Cahuachi y su aspecto monumental despertaron la atención de diversos especialistas desde los inicios del siglo XX. Los trabajos pioneros efectuados por Alfred Louis Kroeber en 1926 y William Ducan Strong entre 1952 y 1953, fueron luego proseguidos por Hélaine Silverman entre 1984 y 1985. Sin embargo, las investigaciones de mayor amplitud vienen siendo realizadas por el CISRAP ${ }^{3}$, dirigidas por Guiseppe Orefici desde 1983 hasta la actualidad.

Diversas interpretaciones, generalmente contradictorias, han sido formuladas a propósito de la función del sitio. Para Strong, Cahuachi fue un asentamiento habitado por una población importante, como lo sugieren la amplitud del sitio, su complejidad y su carácter monumental. Este arqueólogo consideraba Cahuachi como la

\footnotetext{
${ }^{3}$ Centro Italiano Studi e Ricerche Archeologiche Precolombiane.
} 
capital de la cultura Nasca durante su época floreciente (Strong 1957 : 32). John H. Rowe basándose en el abundante material arqueológico disperso sobre la superficie del sitio, planteó la existencia de un gran centro urbano constituido por templos, plazas, cementerios y zonas de hábitat que se extienden por más de $1 \mathrm{~km}$ a lo largo del valle (Rowe, 1963 : 11). Según esta descripción, Cahuachi se clasificaría como una ciudad "acoritica" ${ }^{4}$, es decir ocupada por todas las categorías de la población incluyendo los agricultores $^{5}$. De manera bastante diferente, Silverman considera que Cahuachi fue un sitio exclusivamente ceremonial, siendo parte de los llamados centros ceremoniales aislados (Silverman, 1985 : 92-93). Utilizando la analogía etnográfica, la autora compara Cahuachi con el santuario de la Virgen del Rosario de Yauca, un lugar de procesión anual, situado en medio de un desolado arenal a $30 \mathrm{~km}$. de la ciudad de Ica. Asimismo, ella lo identifica como un centro de peregrinaje, visitado por diferentes grupos Nasca (Silverman, 1986 : 472 ; 1993 : 312-316). Dentro de esta dinámica cada grupo social construyó su propio edificio sagrado; los más poderosos erigieron las estructuras mayores. Mientras que otros monumentos pertenecieron al conjunto de toda la comunidad, como la Gran Pirámide y el Gran Templo (Silverman, 1985 : 93). Para Orefici, Cahuachi constituyó "una capital teocrática”, un centro ceremonial regido por sacerdotes, cuya representación simbólica aparece en la iconografía de la cerámica y los textiles (Orefici, 1993, 2003); al mismo tiempo, no descarta la hipótesis de Silverman (Orefici, 2003 : 91). Contrariamente a los postulados de ciertos investigadores que describen a los Nasca como una sociedad militarista (Proulx, 1968: 97),
Orefici señala que Cahuachi fue un área de paz. Él basa su hipótesis en la ausencia de contextos de fabricación de armas en el lugar (Orefici, 1993). No obstante, en su ultimo trabajo, el autor admite una posibilidad de actividades guerreras en la región de Nasca (Orefici, 2003 : 91).

A pesar de su importancia y su celebridad, el sitio de Cahuachi aún nos es desconocido. Los trabajos de Silverman aportan ciertamente una visión interesante del sitio aunque ellos se fundan sobre datos de excavaciones limitadas. En cuanto a las excavaciones del CISRAP, no obstante su gran envergadura, sus datos no han sido materia de publicaciones sistemáticas.

Los vestigios arqueológicos analizados en este trabajo ponen en debate el aspecto "aislado" del sitio, su dedicación exclusiva al peregrinaje y su supuesta utilización periódica que tiende a clasificarlo como un centro ceremonial "vacío". La cantidad y el carácter de los elementos arqueológicos descubiertos testimonian ciertamente la existencia de actividades ceremoniales omnipresentes, pero igualmente señalan restos de vida doméstica y cotidiana de los ocupantes del sitio; pudiéndose evidenciar que las funciones religiosas y profanas en Cahuachi se encontraban relacionadas. Por otro lado, la organización del espacio del centro ceremonial no pone en evidencia el aspecto urbano del cual hablan los primeros autores. En pleno auge monumental, este centro ceremonial "habitado" ofrece una arquitectura que no puede contener una población densa.

Un centro ceremonial "habitado" se puede definir por oposición a un centro ceremonial "vació”. El secundo concepto se aplica más bien a los lugares sagrados como las colinas, las montañas o las pampas que pueden estar dotados de edifica-

\footnotetext{
4 Rowe definió como ciudad "acoritica" a los asentamientos donde la gente que se dedica al trabajo rural, reside al interior de los centros urbanos de tal forma que los campos no tuvieron residentes permanentes (Rowe 1963: 3).

${ }^{5}$ Ver también Silverman (1985: 88).
} 
ciones simples ${ }^{6}$ y no a sitios con arquitectura monumental.

Al centro ceremonial "habitado" corresponden los asentamientos de carácter religioso político y económico, donde residen la elite dirigente y una población activa. El centro ceremonial está condicionado por su entorno geográfico sagrado y su ubicación regional estratégica. Los recursos de alto potencial que ofrece su territorio, favorecen indudablemente la presencia de una población permanente. Su prestigio tanto religioso como político lo califica como lugar de peregrinaje periódico a donde acudían las diversas comunidades establecidas en su orbita o aun de otras regiones mas alejadas. Su arquitectura monumental y residencial no se estructura necesariamente en todos los casos como una urbe. Sin embargo, el tamaño de los edificios, su trama arquitectónica y los materiales usados reflejan distinciones sociales.

\section{Partiendo de los datos de campo}

Comprendiendo la evolución de Cahuachi a la luz de los descubrimientos arqueológicos se intentará entender la función y el uso del sitio. El análisis se apoya sobre la cultura material descubierta por las excavaciones conducidas por el CISRAP, en las que he participado en las temporadas efectuadas entre 1999 y el 2004, en los sectores del Gran Templo y de la Gran Pirámide. La presente investigación se basa esencialmente sobre mis propias observaciones realizadas en el sitio así como en los estudios del material arqueológico llevados a cabo durante los trabajos de laboratorio en el Museo Antonini. También toma en cuenta el examen de los informes de excavación de los años 1987 a 1998 consultados en la sede del CISRAP en Brescia.
El estudio enfatiza los datos de excavación, independientemente de los modelos teóricos preestablecidos con respecto a los diferentes patrones de asentamientos. En este articulo, no hago referencia a la analogía etnohistórica y etnográfica, sin embargo no rechazo su utilización a condición de que esta no sea el punto de partida de la interpretación. La etnohistoria puede sugerir algunas pistas a la arqueología, constituyendo, así, un valor agregado. Este procedimiento ayudara a elaborar un esquema explicativo de un fenómeno andino dentro de su propio contexto aproximándose en lo posible a su dimensión real. En ciertos casos, las escenas iconográficas de los objetos contribuyeran a consolidar la interpretación.

\section{Cahuachi antes de su época monumental}

Si bien los vestigios más antiguos del propio centro ceremonial, reconocidos por las excavaciones, se remontan a una fecha aproximada de 200 a.C., se sabe que el lugar estuvo frecuentado durante la época Préceramica (Orefici y Pieri, 1989; Isla, 1990; Orefici, 2003). En el sector Y10, en la capa de arcilla natural en la base de una construcción piramidal (la Gran Pirámide 2), han sido descubiertos los fundamentos de una estructura asociada a un enterramiento humano que contenía materiales líticos, malacológicos y restos vegetales, fechados hacia la primera mitad del IV milenio antes de nuestra era?

Las muestras de plantas y de carbón que provienen del sector Y13 datan del 1830+80 a.C. y del $1770 \pm 60$ a.C. (Ziólkowski et al., 1994 : 256, 257; Orefici, 2003 : 100) y testimonian una ocupación o una frecuentación del sitio durante la época denominada como "Formativo Temprano" o "Periodo inicial". En el estado

\footnotetext{
${ }^{6}$ Por ejemplo las estructuras señaladas por Reinhard (1997) en las cimas del Cerro Tunga en Nazca e Illa Kata en Ayacucho que corresponden respectivamente al Intermedio Tardío y al Horizonte Inca.

${ }^{7}$ Nueve dataciones C14 han sido efectuadas en el laboratorio de Gliwice en Polonia por M. Pazdur. Se trata de muestras de carbón de madera, carbón de postes y de madera quemada. Las dataciones se sitúan entre las fechas de 5560 y $4400 \mathrm{BP}$.
} 


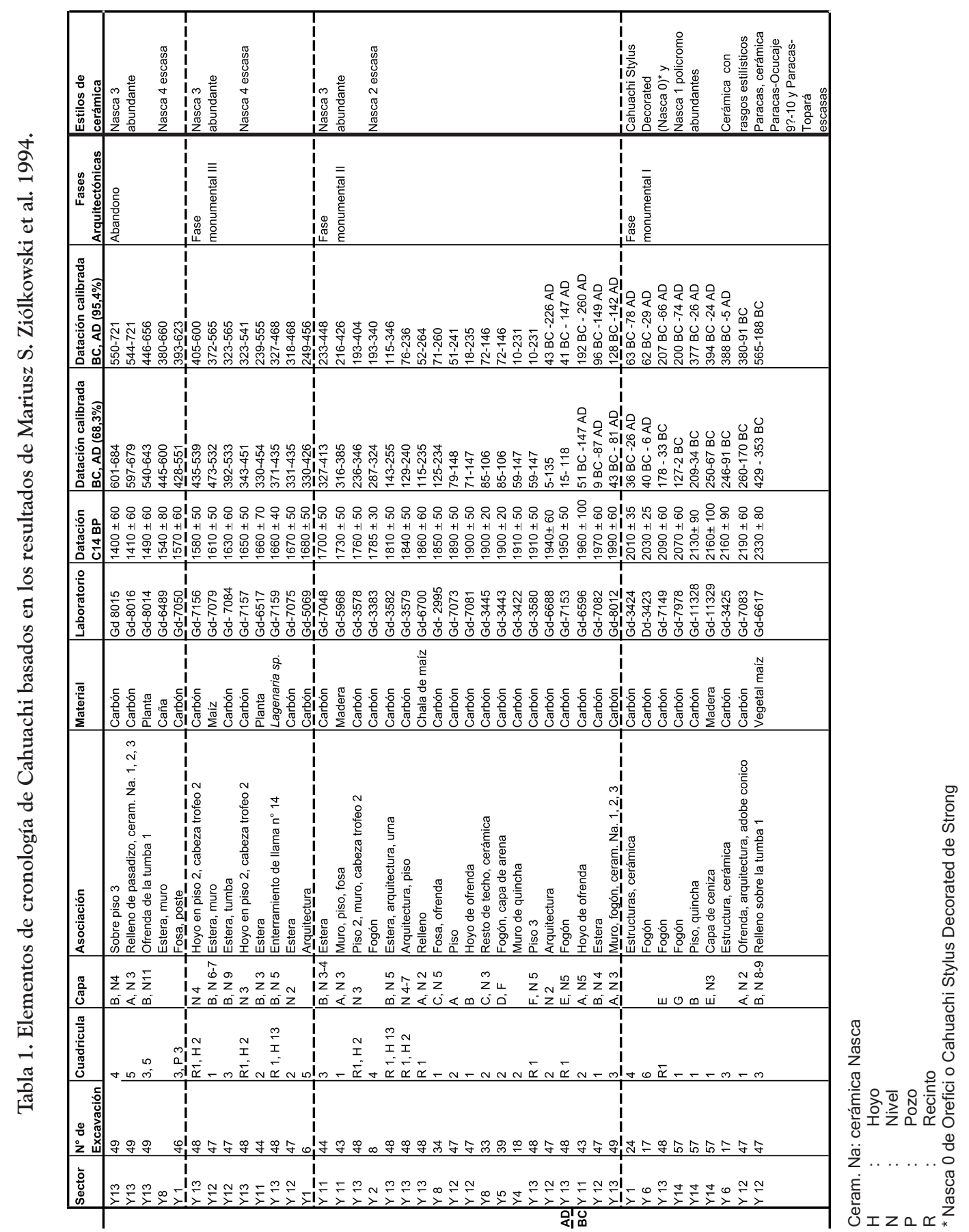


actual de las investigaciones solo disponemos de esas dos fechas, y los contextos fechados presentan muy poco material (fragmentos de textiles y de recipientes de calabazas incisas, restos de plantas cultivadas, huesos de animales, fragmentos malacológicos, restos de carbón y algunos tiestos de cerámica no diagnóstica). La muestra con un fechado de $1830 \pm 80$ a.C. ha sido recolectada en una capa debajo de una estructura en adobes cónicos y paniformes; mientras que aquella con una fecha de $1770 \pm 60$ a.C, se encontraba asociada a un material directamente situado sobre la capa de arcilla natural (plantas cultivadas, huesos, coprolitos de camélido, carbón) sin ningún resto de cerámica ${ }^{8}$. El estado actual de conocimientos no permite definir a qué tipo de ocupación correspondían estas antiguas huellas, las cuales quedan aisladas y fragmentadas.

Una sola datación, $380 \pm 80$ a.C. (Tabla 1) coincide con el llamado "Formativo Tardío" o con el final del "Horizonte Temprano", lo que corresponde en el valle de Ica a la fase media de Paracas Ocucaje. Los restos fechados provenían de un relleno disturbado cubriendo una tumba que contenía tiestos de cerámica mayoramente negra bruñida ${ }^{9}$.

Según Orefici en el sector designado Y 15, construcciones en quincha erigidos sobre la capa de arcilla natural antecedían las estructuras monumentales en adobe ${ }^{10}$. En lo que se refiere a las excavaciones del CISRAP, solo tenemos un elemento estratigráfico limitado a este sector cuyo contexto carece de dataciones. De la misma forma ignoramos el tipo de cerámica asociada a estos vestigios de quincha. Strong señala también un área de casas de quincha tapadas posteriormente para formar la base de un templo en adobes cónicos (Strong : 1957 : 13, Silverman : 1985 : 88). El material asociado a los restos de quincha se caracteriza por una cerámica no decorada y coprolitos de cuy (Cavia porcellus) (Silverman, 1993 : 45). Estas huellas parecen indicar una ocupación domestica como ya lo señalaron los dos autores. Sin embargo, los datos son escasos y limitados para poder entender esta supuesta primera fase constructiva que correspondería a una fecha anterior al 200 a. C.

Por otro lado, el análisis de los materiales de todos los sectores excavados por el CISRAP testimonia la existencia de tres grandes fases sucesivas de construcciones superpuestas, marcadas por remodelaciones entre las cuales dos son mayores. En estas dos se pueden observar cambios en la forma y consistencia de los adobes, en la organización del espacio, así como en la monumentalidad de los edificios. Las dataciones C14 de diferentes materiales indican que el sitio tuvo una ocupación regular e intensa durante el periodo que va del $200 \pm 50$ a.C. al $450 \pm 50$ d.C. (Ziolkówski et al. 1994). Las fechas que se encuentran alrededor de 200 a.C. (Tabla1) concuerdan con el inicio del Intermedio Temprano o del Primer Desarrollo Regional, lo que corresponde a los comienzos de la cultura Nasca en la cuenca del Rio Grande y a la fase tardía Paracas Ocucaje en valle de Ica.

\footnotetext{
8 El informe de excavación de este sector de Cahuachi (Y 13), precisa claramente que la capa C no presentaba ningún resto de cerámica (ver Orefici y Pieri 1993 : 108-109).

9 Este tipo de cerámica es también llamada "Cahuachi Stylus Decorated" y "Cahuachi Black Incised” (Strong, 1957, fig. 9) o "Nasca O" (Orefici,1996 : 193, fig. 6). Materiales similares provenientes de tumbas de la zona de Ocucaje en el valle de Ica (colección Aldo Rubini), han sido clasificados dentro de la fase Paracas T-4, "cerámica negra patrón bruñido” y Nasca 1, "negro ahumado patrón bruñido”, (Menzel, 1971 : 160-161, figs. 6D et 7C).

${ }^{10}$ Orefici, comunicación personal y en curso de publicación. Esta información ha sido igualmente citada en la conferencia de Orefici en el seminario de arqueología, Sorbona-Paris IV, mes de febrero del 2005.
} 

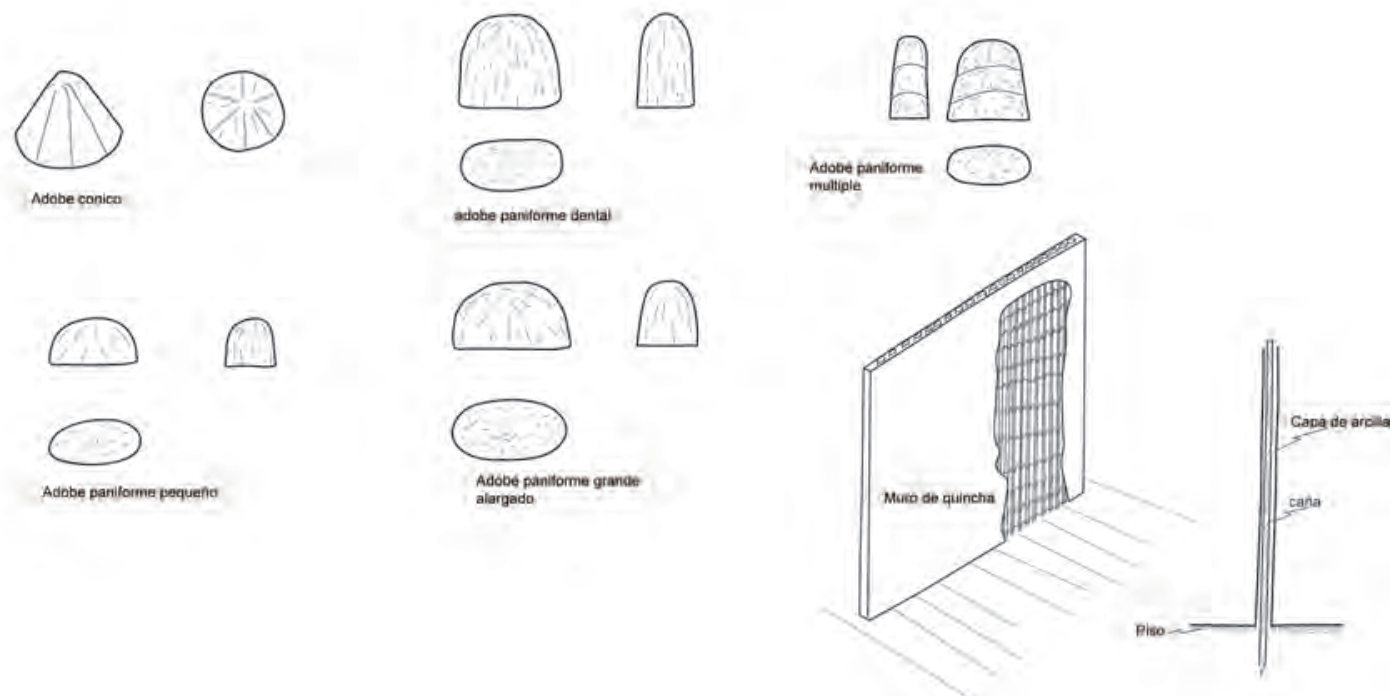

Figura 4. Materiales constructivos usados en Cahuachi, adobes y muros de quincha.

Los inicios del centro ceremonial de Cahuachi; fase monumental I : plataformas aisladas y espacios abiertos

Es difícil por el momento comprender exactamente porqué Cahuachi desde una época temprana sirvió de centro ceremonial de los Nasca. Al respecto, se puede señalar que el lugar se encuentra al borde de un flujo de agua permanente y se presta perfectamente a la ocupación humana. Este territorio se constituye también dentro de una ruta natural que facilita los intercambios entre los sitios Paracas y la sierra de Ayacucho. Los textiles Paracas por ejemplo requerían de la lana de alpaca o de vicuña, un animal cuyo hábitat es la sierra. Los objetos en obsidiana encontrados en sitios Nasca y Paracas testimonian también contactos con esa región. El área de Cahuachi sembrada de colinas y rodeada por las pampas pudo haber tenido un aura particular, como lugar sagrado desde tiempos remotos. En los Andes, las zonas de contacto poblacional y las huacas han facilitado la emergencia de los focos políticos y religiosos cerca de estas áreas.

Teniendo en cuenta los fechados C14 y la cerámica asociada, las primeras construcciones en adobe (Fig. 4) se remontan a un periodo que puede situarse entre el 200 y 100 a. C (Tab. 1, 2). Estas se caracterizan por la utilización de muros hechos con adobes cónicos acanalados, destruidos o reutilizados en parte durante la fase posterior $^{11}$. Las excavaciones han permitido identificar vestigios de estructuras ceremoniales compuestas de una o de dos plataformas que presentan gruesos muros de contención en adobes cónicos de $80 \mathrm{~cm}$. o de $1 \mathrm{~m}$ de ancho y una altura

\footnotetext{
${ }^{11}$ Hemos observado estas evidencias en diversos sectores excavados del Gran Templo y de la Gran Pirámide. Los mismos elementos han sido registrados en Y 12, Y13, Y14, Y15 (ver Orefici y Pieri, 1993, 1995, 1997).
} 
Tabla 2. Tabla recapitulativa de las fases arquitectónicas de Cahuachi.

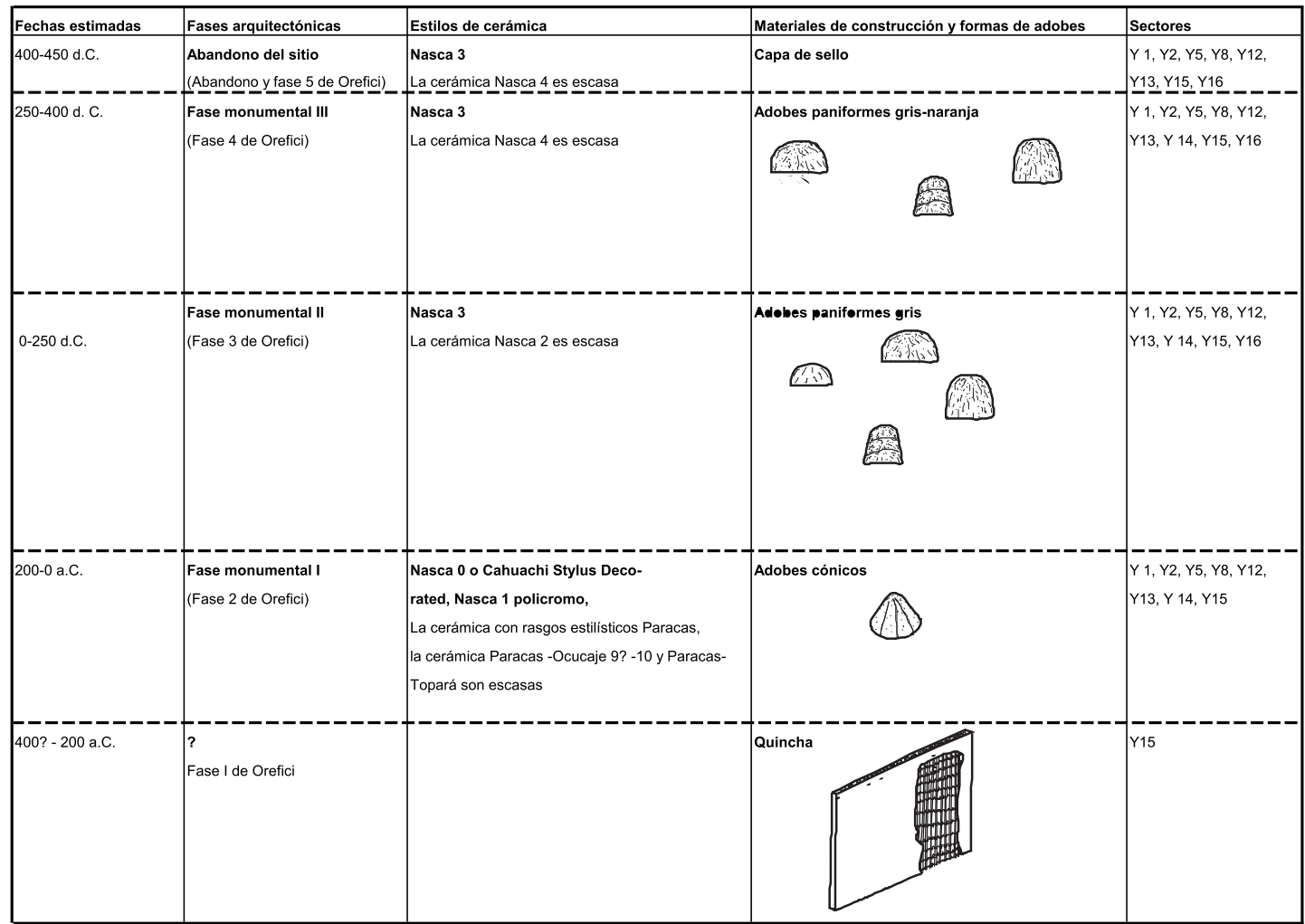

Tabla 3. Características arquitectónicas y domésticas según las fases monumentales de Cahuachi.

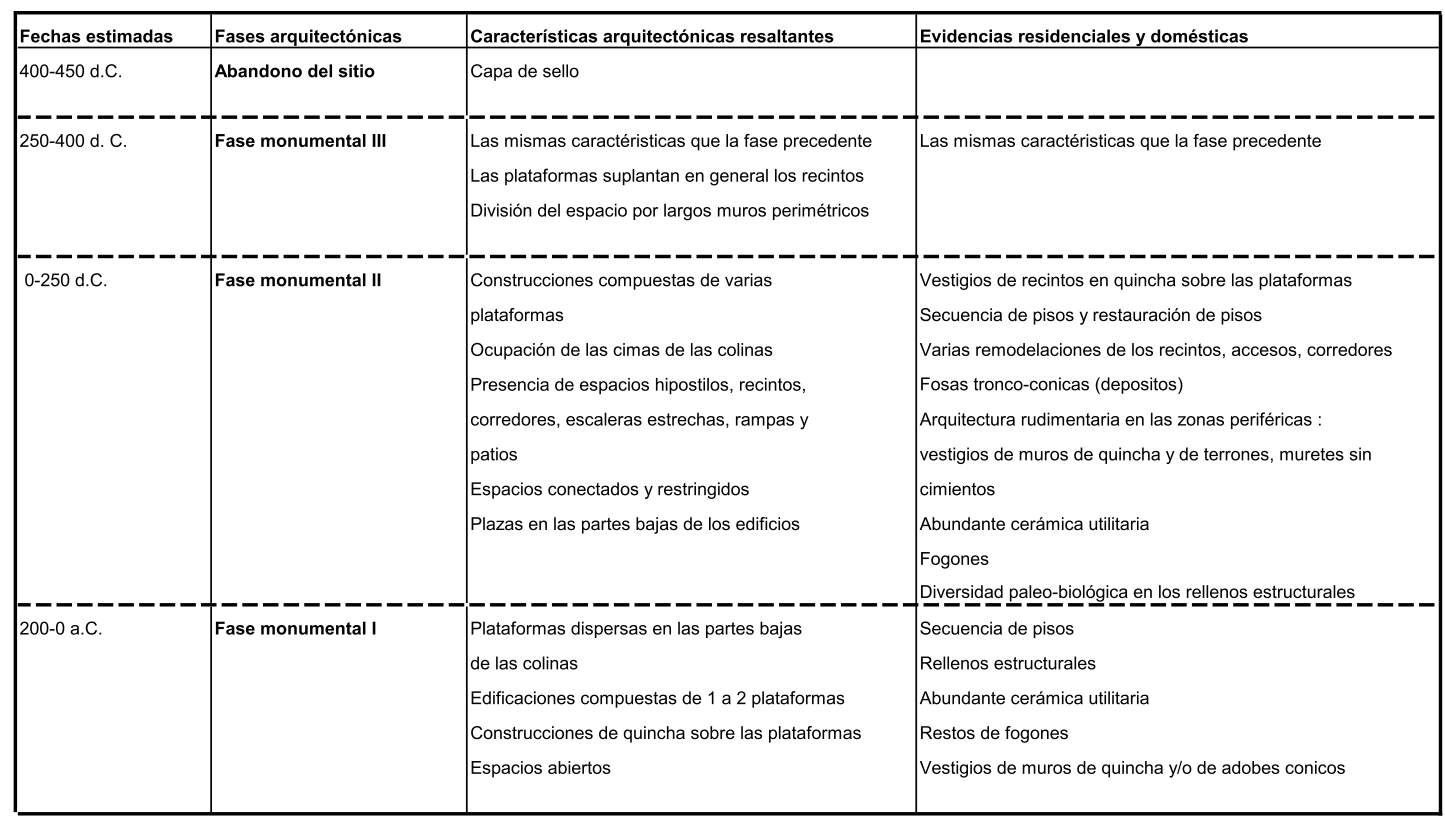


promedio de $3 \mathrm{~m}$ a $4 \mathrm{~m}^{12}$. Según Orefici (2003), la cima de las plataformas contendría recintos en muros de quincha y postes de troncos de huarango que sostendrían techos de paja.

Las plataformas ocupaban de manera dispersa y sin relación entre ellas, las partes bajas de las colinas $^{13}$. La disposición de tales edificios creaba grandes espacios abiertos, probablemente organizados a manera de plazas ${ }^{14}$ ubicadas entre los monumentos. Estas áreas podían servir de lugares ceremoniales que implicaba la participación de un gran número de personas. El tamaño de las estructuras y el modelo de la gestión del espacio sugieren una interacción casi directa entre los dirigentes de las ceremonias, la elite, y los participantes a los ritos, la población en general. La distancia entre estas dos categorías sociales parece menos contundente de lo que ofrece la organización arquitectónica de la fase posterior.

$\mathrm{Al}$ exterior de las plataformas, se hallaron vestigios de viviendas simples al lado de otras construidas con material prestigioso. En diversos sectores (la Gran Pirámide, Y12, Y14) ${ }^{15}$, las excavaciones revelan improntas de postes alineados, excavadas directamente en la capa de arcilla natural. Se encuentran asociadas a restos de muros combinando el adobe cónico y la quincha o bien a paredes compuestas solamente de quincha. Cerca de los campos de cultivo, (sector Y14), también existen vestigios que muestran una acumulación de estratos de ocupación doméstica permanente en vista de la presencia de diferentes pisos superpuestos, de rellenos estructurales y de una gran cantidad de cerámica utilitaria. Los tiestos de cerámica Nasca 1 policroma, negra bruñida o con decoración negativa, son poco representativos. En los niveles más profundos de este sector las excavaciones han puesto a la luz, restos de fogones, un posible espacio de cocina, del cual subsistió una olla y una piedra de batán, colocados directamente sobre un piso y restos de coprolitos de cuy. Diversos pisos así como muros de quincha asociados a muros cónicos presentan trazas de combustión. Estos pavimentos fueron construidos directamente sobre la capa estéril o sobre rellenos estructurales.

La cerámica negra bruñida así como la Nasca 1 policroma se encuentran asociadas y corresponden a la etapa de desarrollo de las antiguas estructuras erigidas en adobe cónico. Paralelamente a estos dos tipos de alfarería, se nota la presencia de cerámica Paracas o con rasgos Paracas, incisa con pintura resinosa post cocción y decorada bajo la técnica del negativo o falso negativo. También se percibe la existencia del tipo Topará. Estos dos últimos estilos han sido encontrados como fragmentos en los rellenos y como recipientes enteros dentro de tumbas y son mucho menos frecuentes que las abundantes muestras de cerámica negra bruñida ${ }^{16}$. Todo indica que alrededor del 200 al 100 a.C. el sitio de

\footnotetext{
${ }^{12}$ Ejemplos visibles de estas construcciones se encuentran en el montículo 1 (Y 1, excavación, 2001) y en el Templo del Escalonado (ver Orefici, 2003 : 75).

${ }^{13}$ En todos los sectores excavados no se notan evidencias de conexiones entre las primeras plataformas en adobe cónico. Ninguna estructura de adobes cónicos ha sido descubierta en las partes altas de las colinas. Los adobes cónicos observados en estas plataformas se encuentran dispersos en los rellenos.

${ }^{14}$ Considero una plaza como un espacio público y un lugar de encuentro. En la mayoría de los casos se trata de un área abierta aunque existen plazas que por su tamaño y sus accesos parecen cerradas y por este hecho relativamente privadas.

${ }^{15}$ Y 12 excavaciones $n^{\circ}$ 47, 51, 54 (ver Orefici et al. 1993, 1997); Y 14 excavaciones n ${ }^{\circ}$ 57, 61, 63, 66 (ver Orefici et al. 1997, 1998, 1999).

${ }^{16}$ En el sector Y1 y en el sector Y13 la cerámica negra bruñida ha sido descubierta sobre los pisos asociados a los muros cónicos. Un cuenco del mismo estilo ha sido descubierto en el sector Y1 debajo de un muro de quincha (Orefici, $1996: 177,193)$.
} 


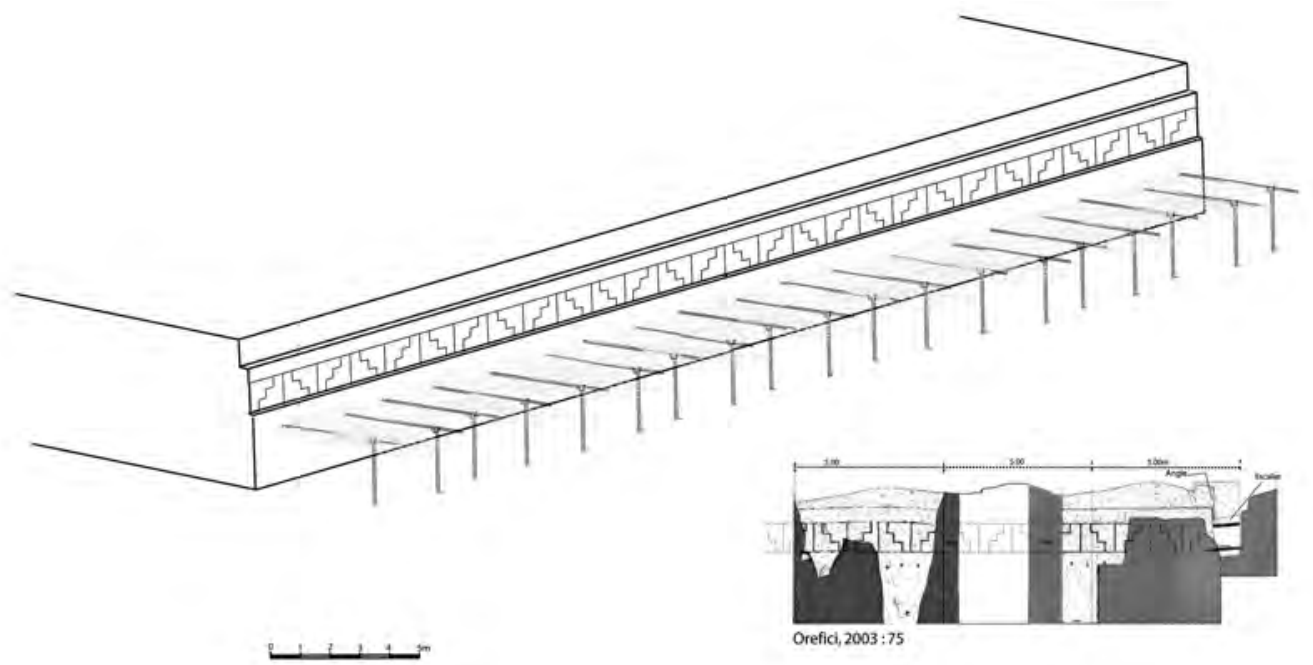

Figura 5. Reconstrucción isométrica de una parte del Templo del Escalonado (Dibujo Bachir Bacha).

Cahuachi detentaba un cierto prestigio, sin duda religioso y político, captando dentro de su orbita de interacción a las poblaciones Paracas. Ello explicaría la presencia de objetos Paracas en Cahuachi.

Durante esta primera etapa, las construcciones de Cahuachi parecen depender de un monumento principal llamado el Templo del Escalonado (Y2) situado al noroeste de la Gran Pirámide y al oeste del montículo 1 (Y1). Este es el único monumento decorado con un friso de grecas $^{17}$ (Fig. 5). También se distingue por su forma paralelepípeda y su plataforma artificial, elevada sobre el suelo natural sin aprovechar el relieve de las colinas que, frecuentemente forman la base y el núcleo de los edificios de Cahuachi. La fachada del Templo del Escalonado presenta a $1.80 \mathrm{~m}$. del piso, las improntas de perforaciones circulares, las cuales indican que el muro soportaba las vigas de un techo situado a un nivel debajo del friso. En un momento dado, a una distancia de $1.50 \mathrm{~m}$. otro muro en adobe paniforme fue construido frente a la pared del friso. Posteriormente el edificio fue enterrado en su totalidad, sirviendo de base o de plataforma a nuevas construcciones conectadas con la Gran Pirámide (Orefici, 1989, 2003). Es importante señalar el cuidado y el esmero practicado por los Nasca a la hora de enterrar el friso del templo. En efecto, a fin de proteger el motivo simbólico se dispuso una capa de arena fina entre el muro decorado y el relleno ${ }^{18}$ colocado frente a la fachada del templo.

El muro paniforme, con enlucido de barro en sus dos caras (Orefici, 1989), no fue elevado exclusivamente para servir como muro de contención del relleno citado líneas arriba, si no que habría sido levantado para formar junto con la fachada del templo, un largo pasadizo techado cuyo acceso al lugar actual de las excavaciones aun se desconoce. Por consiguiente estos dos muros funcionaron en cierto momento en conjunto, lo que indica que el Templo del Escalonado siguió funcionando por un tiempo durante la fase constructiva posterior (fase monumental II). Esta es la prueba de que partes

\footnotetext{
${ }^{17}$ Se ignoran las dimensiones exactas de este templo, ya que solo se ha excavado el frente norte que mide alrededor de $15 \mathrm{~m}$ de largo por $4 \mathrm{~m}$ de altura.

${ }^{18}$ Este relleno esta constituido de adobes, terrones, fragmentos de quincha y cerámica fragmentada.
} 
de algunos antiguos edificios, con fuerte connotación simbólica, se mantuvieron funcionando con los nuevos a pesar de las remodelaciones mayores.

El enterramiento total del templo y el cuidado del friso durante este acto se observa únicamente en este edificio. En todo Cahuachi durante las etapas posteriores, las nuevas estructuras fueron construidas sobre las precedentes en gran parte destruyéndolas, dejando tan solo los pisos y los fundamentos de los muros cónicos. La característica ritual del enterramiento del Templo del Escalonado tiene antecedentes en las épocas Precerámica y Formativa de los Andes Centrales. Por ejemplo en Kotosh, donde el piso y el muro decorado con el friso de las Manos Cruzadas fue recubierto con una gruesa capa de arena fina de río, a fin de proteger los relieves (Onuki, 1993: 80).

El enterramiento simbólico de una estructura ceremonial y la edificación de otra que la reemplaza tienen necesariamente una significación ideológica muy especial. Se trata de una práctica ritual notable en el antiguo Perú, llamada "la renovación de los templos" (Onuki, 1993; Shimada et al. 1982). Ella no tiene como única causa las catástrofes climáticas, aún si la región de Nazca ha estado sujeta frecuentemente a fuertes movimientos telúricos, además de las inundaciones producto de los Mega Niños que han afectado la región. Onuki supone que la renovación del templo seria el primer medio de desarrollo socio cultural. Esta práctica necesita una mano de obra importante que va unida en paralelo a la producción de alimentos y bebidas, así como a una organización del trabajo cada vez más compleja. La renovación del templo ayuda a promover el desarrollo económico, tecnológico, ideológico así como los intercambios entre la costa y la sierra (Onuki, 1993 : 92).
En Cahuachi, se observan remodelaciones que se manifiestan a través de dos grandes modificaciones arquitectónicas y que sin excluir la hipótesis de grandes eventos climáticos, podrían corresponder también a cambios dentro de la estructura política y religiosa. Los nuevos templos parecen regidos por un nuevo polo de poder. En cuanto a las modificaciones que han sufrido los edificios al interior de cada fase, pueden obedecer a eventos cíclicos o a un calendario ritual relacionado al culto de los muertos o de los ancestros de los cuales depende la fertilidad y la abundancia del agua. A parte de esto, se observan refacciones frecuentes de orden funcional ligadas a una obligación de mantenimiento de las estructuras.

\section{El apogeo de Cahuachi; fases monumentales II y III: edificios conectados y espacios restrin- gidos}

\section{Fase monumental II}

A comienzos de nuestra era, la arquitectura de Cahuachi conoció transformaciones importantes. En el conjunto del sitio, los sólidos y espesos muros de un ancho aproximado de $80 \mathrm{~cm}$. a 1 m. construidos con adobes paniformes ${ }^{19}$, se sobreponen o reemplazan en general a aquellos en adobes cónicos, que serán desmontados en parte o recubiertos por rellenos dentro de los cuales se colocaron generalmente ofrendas. Estas se componen esencialmente de recipientes que corresponden a la cerámica negra bruñida, Nasca 1 policroma y restos de grandes ollas.

La arquitectura de Cahuachi prolifera y adquiere un aspecto claramente monumental. Ella se encuentra sistemáticamente asociada a la cerámica Nasca Temprano (fases estilísticas 2 y 3). Los monumentos se caracterizan por ser plataformas de 2 a $3 \mathrm{~m}$. de altura, algunas de las cuales se sobreponen alcanzando en conjunto los 20

\footnotetext{
${ }^{19}$ Los adobes paniformes (en forma de pan), de color gris-beige caracterizan a esta fase. Ellos se presentan bajo diferentes formas: paniformes pequeños, paniformes grandes y alargados, otros son semi lenticulares y paniformes alargados, menos espesos conocidos como múltiples (Fig. 4).
} 

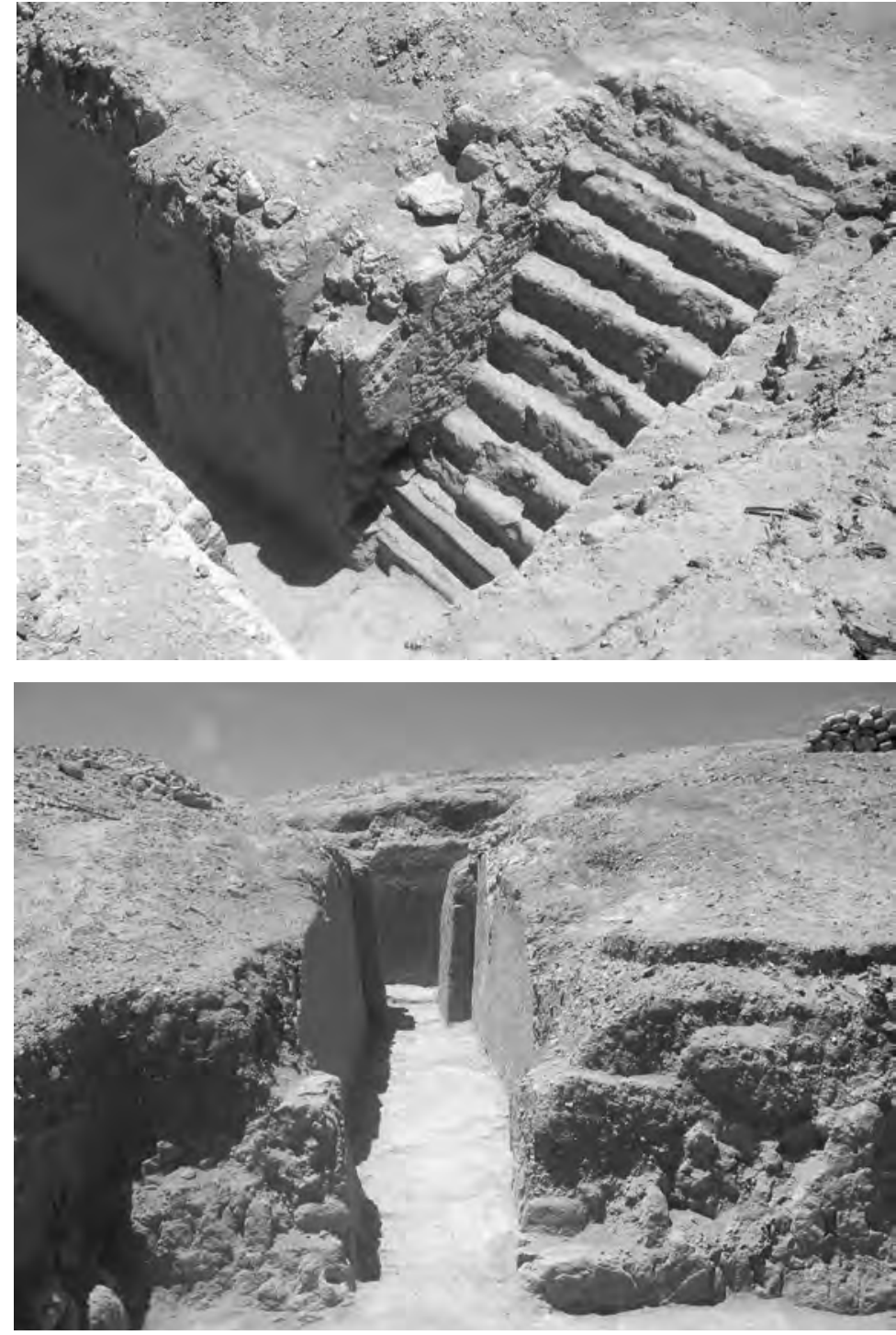

Figura 6. Arriba, pasadizo que conecta a una escalera oculta de 11 gradas. Abajo le escalera que conduce a la segunda plataforma de la Gran Pirámide (excavaciones CISRAP, foto Bachir Bacha, 2003).
CISRAP han demostrado que no existen espacios abiertos entre los monumentos como lo ha indicado Silverman (1986, 1993) y como lo permite pensar la fotografía aérea. Según Orefici (2003) terrazas intermedias y plazoletas accesibles a través de pasadizos, escaleras o rampas, articulaban estas construcciones.

Durante esta etapa, la zona central de Cahuachi parece constituirse progresivamente en un complejo de edificios cada vez más estructurado y cerrado. Tal arquitectura contrasta sensiblemente con aquella de la fase precedente. La nueva organización arquitectónica delimita áreas reservadas a un número restringido de personas, permitiendo una circulación reducida. La existencia de corredores y de escaleras estrechas de un ancho aproximado de $80 \mathrm{~cm}$., ubicados en diversos sectores de Cahuachi y especialmente en las partes altas del Gran Templo, de la Gran Pirámide, y también dentro de estructuras menos imponentes como el montículo 1(Y1) y el sector Y16, confirman dicha tendencia. m es el caso de la Gran Pirámide y el Gran Templo. Sobre dichas construcciones se advierten recintos, patios ${ }^{20}$, corredores, escaleras de conexión (Fig. 6) y rampas. Las excavaciones del
Los recintos y las galerías levantados sobre las plataformas al interior de los edificios son construidos en adobes paniformes o en quincha. Sus techos son sostenidos por postes de huarango. Estos espacios han sufrido una gran cantidad

\footnotetext{
${ }^{20}$ Un patio corresponde a un espacio abierto (sin techumbre o parcialmente techado) que esta delimitado y se encuentra dentro de una estructura. Las actividades que se realizan en él suelen ser de carácter privado.
} 
de remodelaciones, algunos de sus accesos fueron reducidos de tamaño o bien fueron clausurados y sus postes seccionados y quemados. Todos los ambientes podían ser cubiertos por rellenos a fin de reorganizarlos. Se ha registrado igualmente una sucesión de diversos pisos restaurados.

En la quinta plataforma de la Gran Pirámide fueron descubiertas bases circulares en arcilla que funcionaban como zócalos de los postes. Ellos están asociados a diversos pisos sobre los cuales se encuentran a veces lentes de ceniza. Los pavimentos señalados son quizás parte de los vestigios de las construcciones de quincha. La gran cantidad de restos de muros de quincha utilizados en los rellenos que cubrieron los recintos de la fase monumental II confirma la existencia de estructuras habitacionales. Se trata de un hábitat reservado a un grupo reducido sin duda la elite dirigente. Esto no impide el hecho que otros espacios o los mismos, al interior de los edi- ficios hayan estado destinados a la realización de ceremonias.

El gran recinto descubierto en la cima del Gran Templo, imperceptible del exterior, funcionó como un espacio de hábitat o de reunión privada (Fig. 7). El se encuentra conectado por pasajes estrechos que permiten el desplazamiento de una persona a la vez. Juzgando por las ofrendas (antaras fracturadas, una gran olla, una cabeza trofeo mirando hacia el este, un tambor) descubiertas sobre el piso de una entrada hipostila (Fig. 8), situada en la segunda plataforma del Gran templo, el lugar fue el escenario de celebraciones de ritos privados (Bachir Bacha y Llanos, 2006).

La frecuencia de corredores estrechos puede haber servido paralelamente a la comunicación y al desarrollo de ritos. Podemos pensar en procesiones de personas que circulaban en fila india de un espacio al otro, a través de los accesos, las esca-

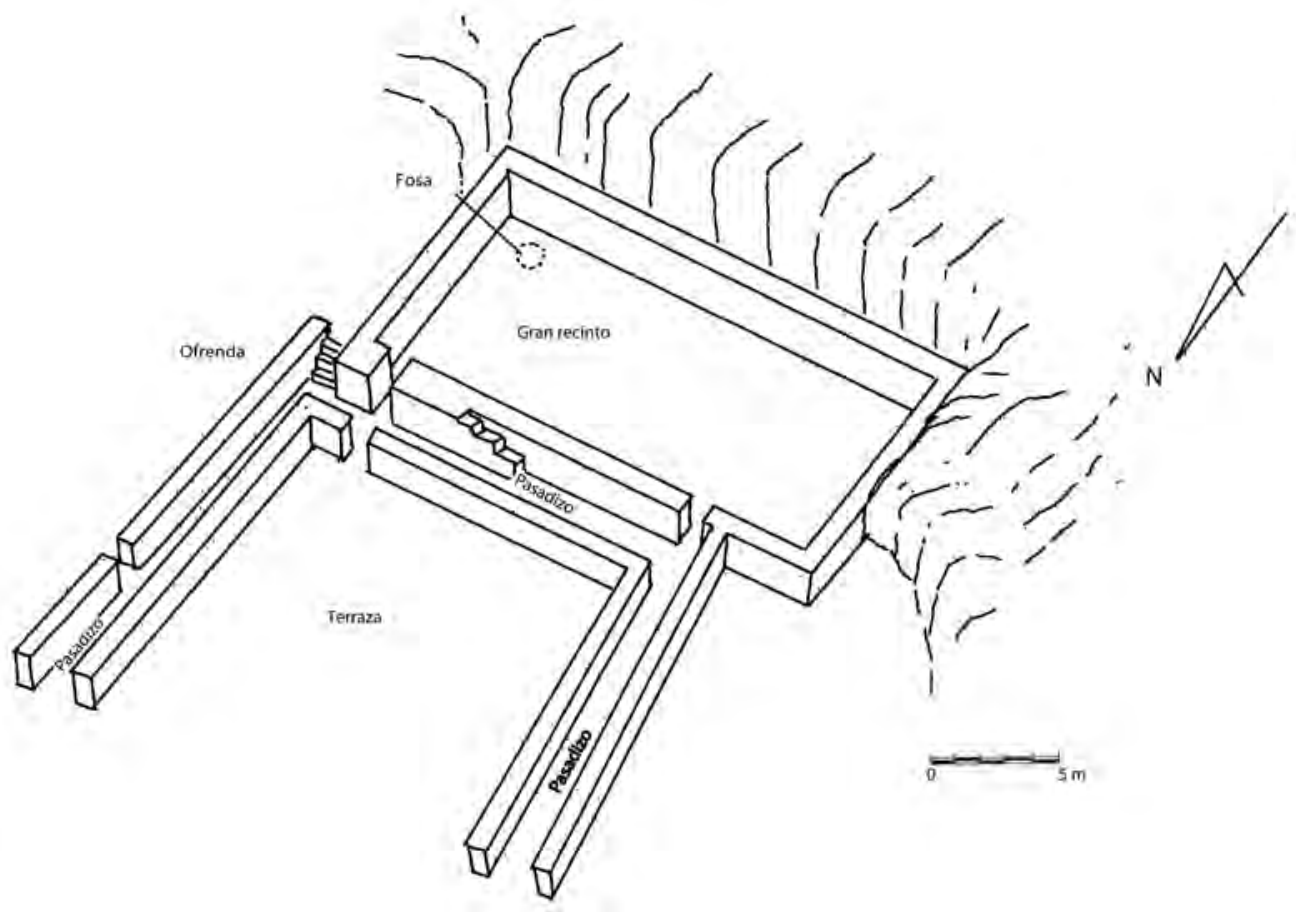

Figura 7. Reconstrucción isométrica de las estructuras descubiertas en el sector superior del Gran Templo. Fase monumental II (Bachir Bacha y Llanos, 2006). 


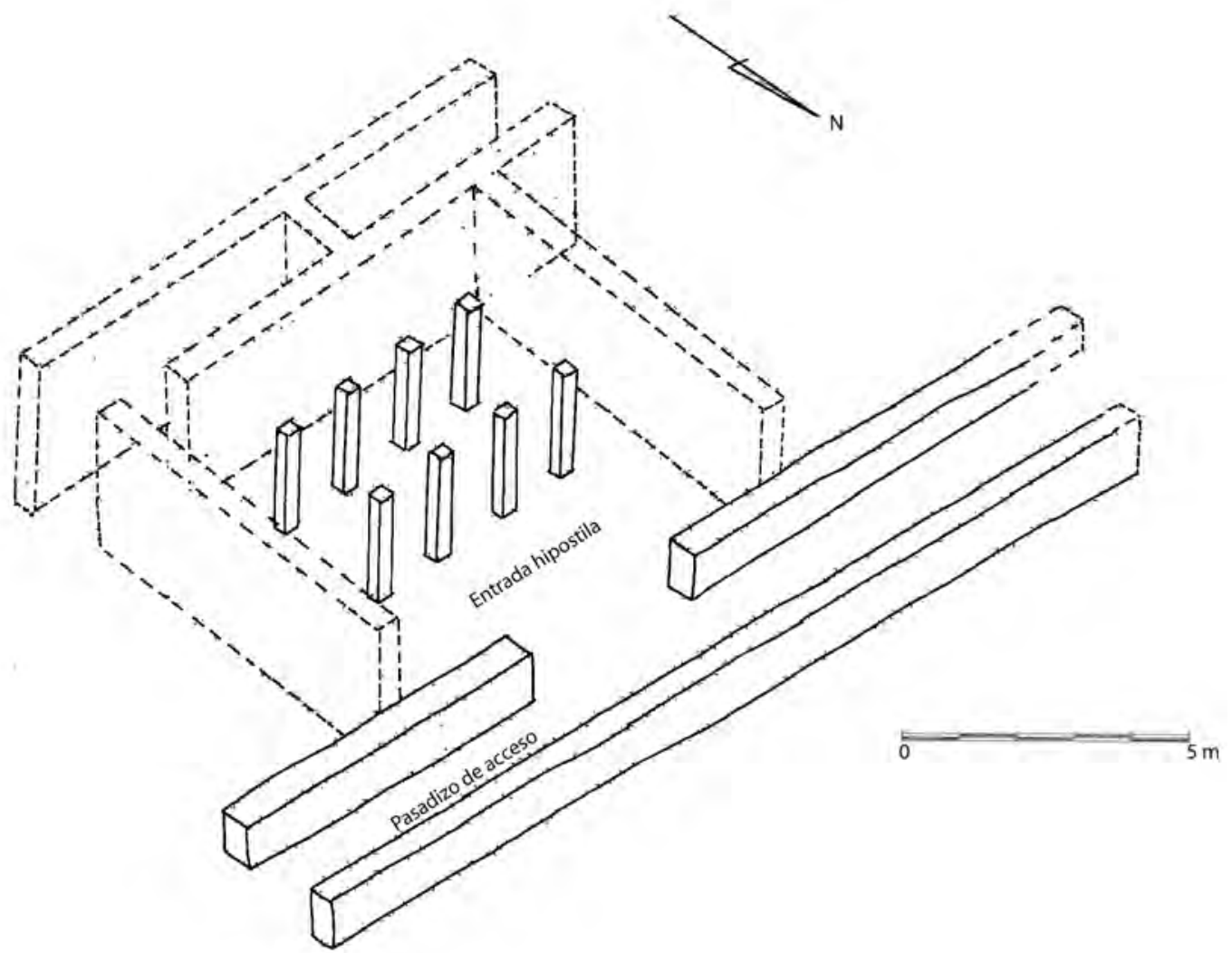

Figura 8. Reconstrucción isométrica de la entrada hipostila en la segunda plataforma del Gran Templo. Fase monumental II (Bachir Bacha y Llanos, 2006).

leras y los pasajes entre las diferentes terrazas y los edificios que se encontraban continuamente conectados. Se trata seguramente de ceremonias particulares limitadas a los dignatarios. En efecto, existen en la iconografía Nasca diversas representaciones de personajes que portan cabezas trofeo o plantas, mientras que otros aparecen frente a escaleras como si se dirigieran a entrar en ellas. El fragmento de un textil Nasca (Alan Sawyer, 1997: 112, fig. 80) muestra unos individuos con rasgos felinicos, ricamente vestidos, situados en proximidad de una escalera de 11 peldaños, uno de los personajes porta un felino y el otro lleva aparentemente un hombre (un guerrero?). Tal escena recuerda un acceso principal en forme de L de la Gran Pirámide, compuesto por un pasaje que da a una escalera oculta de 11 gradas (Fig. 6).

Plazas (45 m. x $30 \mathrm{~m}$.) adyacentes a las partes bajas de los edificios principales, como es el caso de la Gran Pirámide (excavaciones del 2004) se encuentran unidas a las plataformas a través de accesos en forma de L que llevan a escaleras ocultas, las cuales permiten el paso hacia las terrazas y a los recintos situados sobre las plataformas. Los anchos corredores (aprox. $2.50 \mathrm{~m}$.) contiguos a las plazas, contrastan con aquellos descubiertos en las partes altas al interior de los edificios. De ahí deducimos que en esos espacios públicos se desarrolló ceremonias que implicó mayor congregación de individuos. Es el caso de la gran plaza del Gran Templo (90 m. x 30 m.). 
Figura 9. Sección de muro en
adobes paniformes dañado por
el escurrimiento de agua
(excavaciones CISRAP, foto
Bachir Bacha, 2004).

\section{Fase monumental III}

Alrededor de 250-280 d.C., los monumentos de Cahuachi sufren importantes remodelaciones. Un terremoto y desbordes torrenciales alteran las construcciones. Las huellas de estas catástrofes naturales han sido observadas durante las excavaciones de la Gran Pirámide (Fig. 9) y en los sectores Y13, Y15, Y16.

Es durante este momento que comienza el recubrimiento de las antiguas estructuras por medio de rellenos y las construcciones de nuevas edificaciones, formadas por plataformas y terrazas. La presente etapa de construcción se caracteriza igualmente por la utilización de adobes paniformes de gran talla (ancho $40 \mathrm{~cm}$., espesor 15 a $25 \mathrm{~cm}$., altura 25 a $30 \mathrm{~cm}$.), de colores gris y naranja, mas frágiles que los de la etapa anterior. Generalmente estos adobes forman muros periféricos y se agregan a los muros de contención de rellenos de la etapa anterior. Los delgados muros divisorios fabricados con una sola hilera de adobes (Fig. 10), no parecen tener una altura superior a 1 metro. Se observa que ciertas estructuras y muros de la fase precedente perduran (Y1, Y16, la Gran Pirámide). La cerámica mayoramente de estilo Nasca 3 corresponde a este tipo de arquitectura.

Gran parte de los recintos de la etapa anterior son recubiertos luego de haber sido desmontadas algunas partes de sus muros y de haberse efectuado limpiezas totales de ciertas zonas. Diversas ofrendas son dispuestas sobre los pisos y dentro de los rellenos. Se trata de recipientes de cerámica decorada o de grandes ollas, mates, animales (perros, llamas, cuyes, loros, halcones), bastones de madera bien pulidos (Fig. 11), paquetes de textiles, y también de sacrificios humanos y cabezas trofeo. Entre los descubrimientos múltiples se destaca uno ubicado en la primera plataforma del Gran Templo. Durante el desmantelamiento y el recubrimiento de un ancho pasadizo, un paquete de dardos, una cabeza trofeo, una botella de dos picos y asa puente Nasca 3 y cuerpos humanos, sin duda de sacrificados, fueron colocados alternativamente al interior y al exterior del corredor ${ }^{21}$ (Bachir Bacha y Llanos, 2006).

El recubrimiento de los grandes recintos a fin de lograr nuevas plataformas, está ligado sin duda a un cambio de uso del espacio. Evidentemente los arquitectos de esta etapa tratan de crear áreas ceremoniales más vastas. Pero del mismo modo estos sectores quedan

\footnotetext{
${ }^{21}$ Un paquete de dardos al exterior norte del pasadizo; una cabeza trofeo, una momia decapitada y otra de una mujer con ofrendas al interior del corredor; mientras que al exterior sur de esta galería los restos de la botella a doble pico y asa puente.
} 
reservados a los conductores de los ritos que dan la impresión de querer mostrarse durante las ceremonias. El espacio hipostilo de la quinta plataforma de la Gran Pirámide construido durante la fase precedente, será dividido por pequeños muros creando así seis recintos abiertos hacia el valle (Fig. 10). No obstante, se observa que las áreas reservadas al hábitat subsisten.

Las excavaciones efectuadas en el 2003 en la sexta plataforma de la Gran Pirámide revelan restos de una pieza construida con muros de quincha, que presenta tres hileras de postes con bases cuadradas de barro. La superposición de diversos pisos es un testimonio del uso permanente de este sector. En la primera plataforma del Gran Templo fueron descubiertas tres pequeñas terrazas (Fig. 12) incluyendo los restos de recintos (aproximadamente de $6 \mathrm{~m}$. x $5 \mathrm{~m}$.) con sus pisos deteriorados.Sobre la plataforma superior del Gran Templo, la excavación revela una gran terraza sobre la cual yacían los restos de muros de quincha derribados y que presentaban trazas de fuego. Igualmente se observaron hoyos de pos- tes, pruebas de la existencia de un ambiente techado. Durante esta época, el paisaje de Cahuachi es dominado por diversas pirámides escalonadas. Largos muros perimétricos encierran los edificios del sector central, occidental y la Gran Pirámide 2 (Fig. 2). Los monumentos de Cahuachi adoptan la forma escalonada, simbología que se encuentra como uno de los motivos principales de la cerámica y los textiles. En Cahuachi las estructuras escalonadas aparecen desde la primera fase, pero toman una importancia mayor durante la fase monumental II. Es evidente que el símbolo de la greca escalonada esta ligada a la arquitectura piramidal y esta a la representación del poder. Este símbolo es continuamente representado en las vestimentas y los cascos de las divinidades o de los personajes de alto rango ( ver figuras en Lavalle, 1986: 117; Tello, 1959: fig. LXXXI; Sawyer, 1997: 67, 112).

La arquitectura de la fase monumental III, tal como la precedente implican una gran distancia entre los protagonistas de las ceremonias y los asistentes. Las plazas situadas en las partes bajas

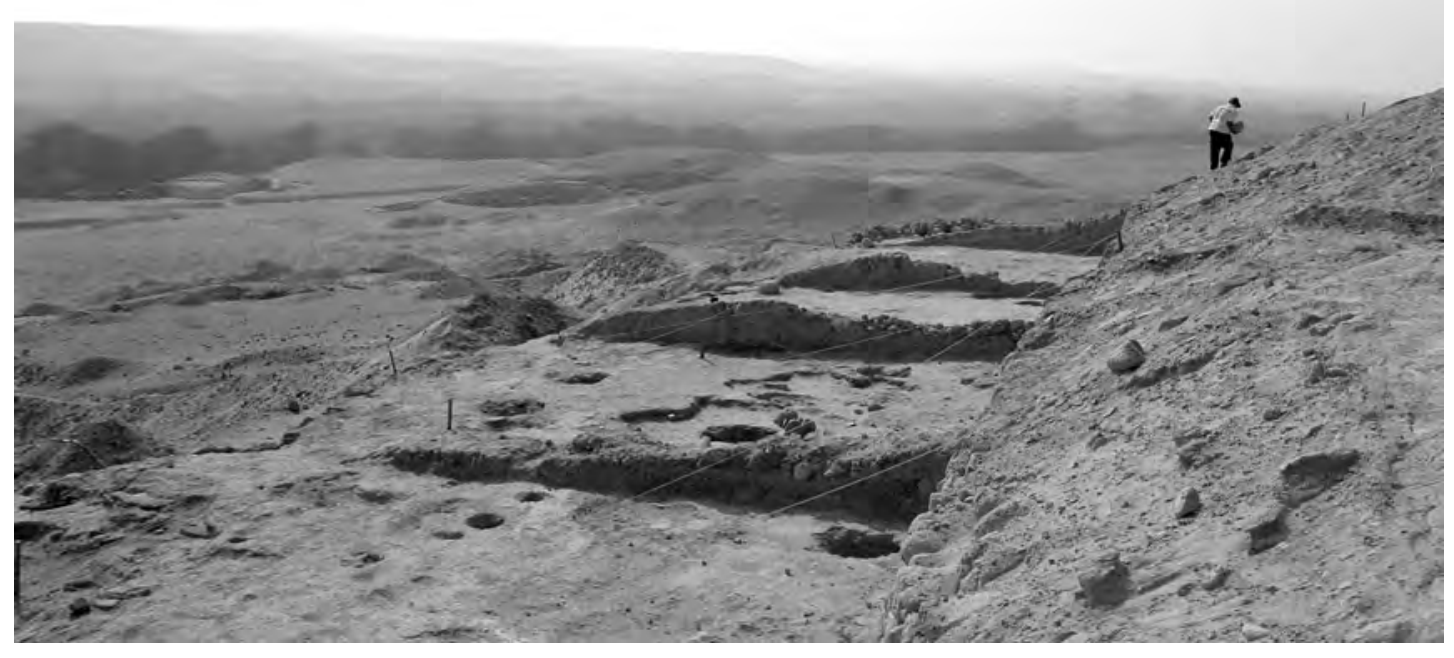

Figura 10. Vestigios de muros de recintos sobre la quinta plataforma de la Gran Pirámide (excavaciones CISRAP, foto Bachir Bacha, 2004). 
de las pirámides guardan una mayor distancia con respecto a los recintos habitacionales y/o ceremoniales, ubicados al interior de los edificios. Se puede establecer entonces una dinámica de ceremonias intimas reservadas a los dignatarios y otras de cierta forma abiertas, dirigidas hacia el gran público y que se desarrollaban sobre las terrazas. La música por intermedio de tambores, antaras, silbatos, objetos largamente registrados en los contextos

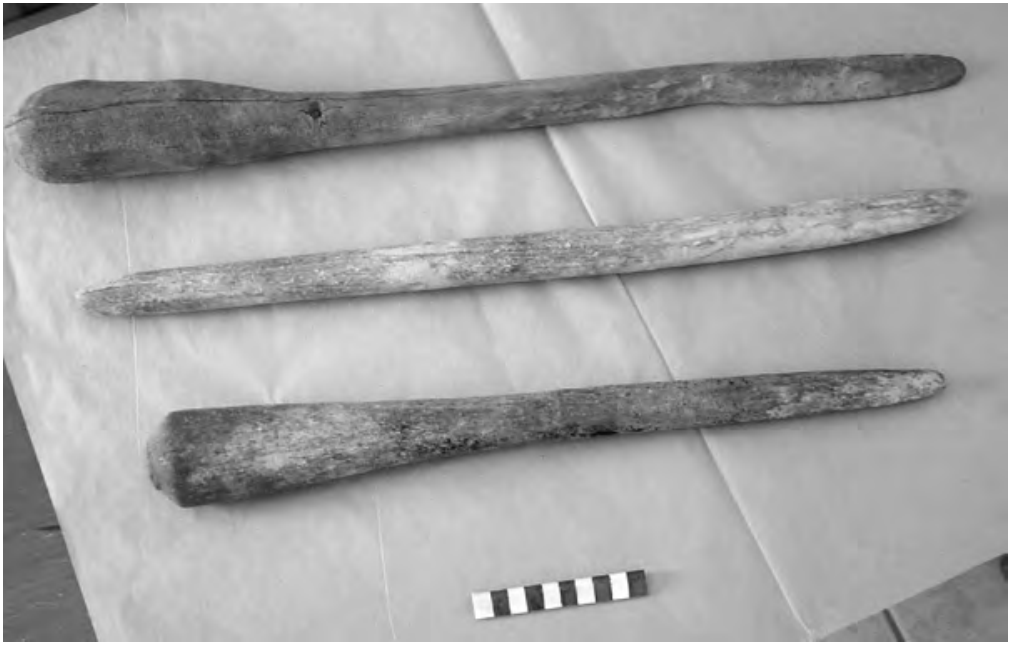

Figura 11. Bastones pulidos descubiertos en las plataformas de la Gran Pirámide (excavaciones CISRAP, foto Bachir Bacha, 2004). arqueológicos y representados en las escenas iconográficas, debió ser el medio de comunicación privilegiada. Se agregaban a ello la escenografía, los atuendos de gala, así como el fuego, cuyas trazas de fogones han

sido observados sobre diversas plataformas. Las plazas debieron ser también el teatro de festividades específicas, pienso en particular en combates rituales.

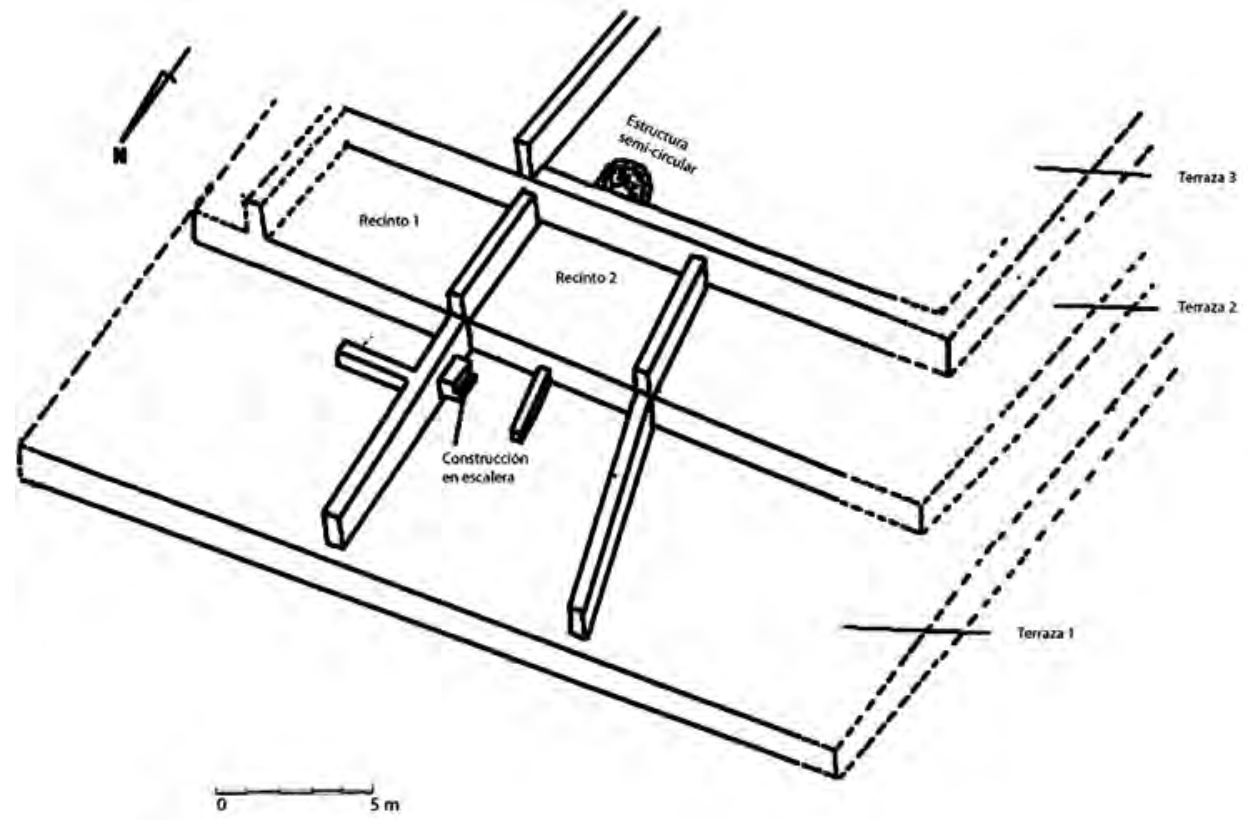

Figura 12. Reconstrucción isométrica de las estructuras descubiertas en la periferia nor oeste, sección baja del Gran Templo. Fase monumental III (Bachir Bacha y Llanos, 2006). 
Cahuachi, centro ceremonial "habitado": manifestaciones de vida política y económica

Como ha sido mencionado al inicio del artículo, Silverman considera Cahuachi como un centro ceremonial aislado, lo que en su terminología indica que se encuentra fuera de redes de comunicación. Sin embargo, la autora no excluye la posibilidad que las pampas que rodean Cahuachi, con sus inmensos geoglifos, hayan servido como caminos de acceso al centro ceremonial para eventuales peregrinajes (Silverman, 1985: 92).

La tesis que concibe Cahuachi como un sitio aislado es discutible. En efecto, él se encuentra cercano a otros establecimientos Nasca contemporáneos, situados a solo algunos kilómetros (dentro de un radio de 2 a $10 \mathrm{~km}$ ), como Las Cañas, Estaqueria ${ }^{22}$, Pueblo Viejo, Usaca, Jumana. Además el sitio se encuentra conectado al de La Ventilla a través de un largo geoglifo (El camino de Leguía) de $11 \mathrm{~km}$.

Sin equivocarse, podemos pensar que la población de los establecimientos vecinos tomaba parte diariamente en el sistema económico de Cahuachi y de hecho se trasladaba allá frecuentemente. Por otra parte, el calendario en uso obligaba a los diferentes grupos de los diversos valles a desplazarse según periodos bien establecidos para participar en las ceremonias del culto o para compartir las obras de construcción o de remodelación de los templos. Así la idea del peregrinaje de Silverman puede tener sustento.

Sin embargo, es difícil plantear la idea de un centro ceremonial « vacío ». La función ceremonial o de centro de peregrinaje no impide que el sitio haya sido ocupado y habitado de forma permanente. Sin duda por una clase de lideres con funciones religiosas y también guerreras, teniendo en cuenta la importancia de este fenómeno dentro la sociedad Nasca (Bachir Bacha, 2006). Los datos actuales no permiten de precisar si se trata de un gobernante y su séquito o de un gobernante y su familia. La iconografía de los objetos descubiertos a Cahuachi ilustra personajes de pie portando mascaras, diademas, collares y aretes formados en varios círculos, exhibiendo en sus manos bastones y empuñando cabezas trofeos, atributos que simbolizan el poder. Los espacios domésticos de la elite debieron ser áreas de reunión restringida, de descanso y de depósito. Sobre diversas plataformas y en particular en la Gran Pirámide y el Montículo 1, han sido descubiertas grandes fosas tronco cónicas $(60 \mathrm{~cm}$. de diámetro y $80 \mathrm{~cm}$. de profundidad) que han podido servir de depósitos de alimentos y otros materiales ${ }^{23}$.

Entorno a esta clase de gobernantes, una población no densa pero estable de artesanos, agricultores y otras categorías participaba continuamente al funcionamiento, a la producción y el mantenimiento del sitio. Las evidencias de sus aéreas de hábitat han sido observadas en la periferia de los principales edificios.

Los artesanos especializados en la fabricación de la parafernalia de culto desempeñaban un papel importante en la dinámica del sitio. Un variado material descubierto sobre los pisos de los recintos y no dentro de rellenos, compuestos de pulidores, espátulas, conchas que contenían pigmentos, pinceles, valvas de spondylus y de textiles preparados para ser bordados (Orefici, 2003: 70), indica claramente el desarrollo de una actividad artesanal local controlada por la elite dirigente. No es sorprendente que las estructuras

\footnotetext{
${ }^{22}$ Estaqueria es atribuido al Horizonte medio. No obstante, las ultimas excavaciones efectuadas por el CISRAP ponen en evidencia una ocupación Nasca Temprano, Medio y Tardío (Y 17, excavación 64 y 68, Orefici et al. 1998, 1999).

${ }^{23}$ Próximas a estas fosas se han registrado grandes pedazos de cerámica. Según Llanos, jefe de sector de excavación en la Gran Pirámide, Gran Templo y el Montículo 1, estos gruesos fragmentos de cerámica serian parte de las vasijas que, colocadas al interior de las fosas, cumplían un rol de depósito de agua.
} 
menores donde fueron descubiertas las huellas de fabricación de cerámica y de textiles ceremoniales tengan el aspecto de pequeños templos adyacentes a las grandes pirámides, puesto que estos artesanos con su producción sostenían las prácticas rituales.

Es muy probable que el cultivo de algodón haya sido practicado en las tierras agrícolas de Cahuachi. Gran cantidad de granos y motas de algodón han sido recolectados en el sitio, así como restos de lana de camélido sin tratar. Una buena parte de la producción de algodón y de lana de camélido debió haber sido destinada a la producción de textiles ceremoniales y a la vestimenta de los dignatarios. Los 63 paquetes de textiles descubiertos en el sector Y16 contenían vestimentas de color azul, verde, naranja, marrón y gris. Estos atuendos estaban adornados de plumas y de una rica iconografía que representa aves devorando plantas, animales u hombres. Aparecen igualmente serpientes con rostros del felino mítico ${ }^{24}$.

El notable hallazgo de 64 llamas así como diversas ofrendas de cuyes (Orefici, 1994, 2003) es prueba de la importancia ritual de la llama y de la presencia de ganadería en el sitio o en sus alrededores cercanos. El análisis de inserciones musculares de los huesos de las llamas sacrificadas muestran que no habían sido animales de carga ni habituados a largos trayectos (Orefici, 2003 : 100). Probablemente su crianza como la del cuy se hizo in situ.

Los espacios domésticos como aquellos vinculados a la producción de alimentos y de viviendas sencillas se distinguen en las zonas periféricas a los templos o en las proximidades de los campos de cultivos al sitio. Al respecto, en el sector Y11 en la periferia de Cahuachi se ha detectado una ocupación domestica, al oeste de la zona B, cerca de la torre de alta tensión que se encuentra camino a Estaquería. Allí, los estratos presentan lentes de ceniza, huesos de camélidos, moluscos, cerámica Nasca 1, 2 y 3, así como una olla conteniendo corontas de maíz. La arquitectura es rudimentaria, compuesta de muros de quincha y la reutilización de adobes con terrones para construir muretes sin cimientos. A la hora del abandono de Cahuachi, este ambiente fue enterrado y se colocó una cabeza trofeo (Orefici y Pieri, 1993).

El sector Y14* (excavación 63) mencionado anteriormente por su secuencia ininterrumpida de pisos y rellenos, ofrece en los niveles superiores vestigios de recintos en adobes paniformes sin enlucido, con sus pisos deteriorados. Los restos materiales encontrados en un relleno que soporta y cubre estas estructuras asociadas a la cerámica Nasca 2 y 3, se componen de textiles llanos, de vegetales comestibles, fogones así como diversos artefactos de producción de alfarería. Entre ellos pinceles, fragmentos de pigmentos, cerámica modelada no cocida, instrumentos de incisión, abundante cuero y pelo de camélido. Aparte de ello se ha registrado una buena cantidad de huesos cocidos de camélido, de cuy y de pescado así como coprolitos de lama y de cuy. Estos datos atestiguan la presencia de ambientes con funciones domesticas y artesanales.

En los rellenos estructurales que pueden alcanzar tres metros de altura, se han descubierto en gran cantidad toda suerte de materiales que testimonian actividades cotidianas; fragmentos de cerámica utilitaria, de tejidos de tela llana, de muros de quincha y otros objetos domésticos, como peines, pedazos de batanes, morteros y restos de cestas. Se encuentran para-

\footnotetext{
${ }^{24}$ Este material esta en curso de análisis y será objeto de una publicación detallada por Orefici y Frame. Guiseppe Orefici ha tenido la gentileza de mostrarme algunos especimenes de estos textiles depositados en el Museo Antonini.

* Ver nota 15.
} 
lelamente abundantes coprolitos de llama y de cuy, desechos alimenticios como huesos de camélidos, de cuyes quemados o cocinados. Analizando el inventario de los materiales descubiertos en Cahuachi, se observa una gran proporción y diversidad de restos vegetales, entre los que sobresalen el fríjol [Phaseolus vulgaris], el pallar [Phaseolus lunatus], el maíz [Zea maiz], el maní [Arachis hypogea], el camote [Ipomea batatas], la yuca [Manihot esculenta], el zapallo [Cucúrbita máxima], el pacae [Inga feullei], el ají [Capsicum frutescens], etc.

Otro argumento que sugiere que Cahuachi ha sido un centro ceremonial constantemente habitado se deduce de los efectos climáticos sobre la arquitectura. Los edificios sufren continuamente del enarenamiento y del intemperismo, requiriendo necesariamente de un mantenimiento cotidiano. Las frecuentes remodelaciones, los grandes trabajos que han necesitado los templos, implicaron la disponibilidad en el área y en su cercanía de trabajadores especializados. Hoy en día los agricultores ocupan diversos sectores del valle en la inmediación de Cahuachi, y es difícil pensar que estas tierras cerca de una fuente de agua permanente hayan estado visitados solamente de vez en cuando durante la época Nasca.

Basándose en estos elementos podemos descartar la hipótesis de Silverman, fundada en el uso periódico del sitio y su apropiación selectiva, donde cada grupo social construía su propio templo, siendo que los mas fuertes erigían los edificios mas grandes (Silverman, 1985). Un modelo inspirando en la interpretación tradicional de los templos de Pachacamac. No obstante las nuevas interpretaciones a propósito de las pirámides con rampa de Pachacamac indicarían que ellas constituyeron palacios construidos por los "señores" locales y no correspondieron únicamente a templos o áreas de abrigo de los peregrinos (Eeckout, 1998, 1999).

\section{El abandono de Cahuachi: el enterramiento ritual de los templos}

El abandono del sitio de Cahuachi generalmente es explicado como el resultado de un proceso de catástrofes climáticas que afectaron la región. Una secuencia de fuertes precipitaciones y periodos de sequías se inscriben en efecto en los perfiles estratigráficos de tres sondeos geológicos efectuados en la parte baja del cono de deyección del valle "gran quebrada" de La Muña (Reindel e Isla, 2001 : 311).

Los estudios geológicos relacionados con las dataciones C14 indican que la región sufrió tres eventos de precipitaciones catastróficas generadas por el fenómeno del Niño, provocando gigantescas avenidas de barro y lodo. La primera se sitúa aproximadamente entre el 100 a.C., la segunda a mediados del 600 d.C. y la tercera bordeando los 1000 d.C. (Grodzicki, 1994). Entre el 100 a.C. y el 600 d. C., otras inundaciones periódicas tocaron también la región. Sus trazas han sido registradas en el Gran Templo (Y5), así como en los sectores Y1, Y13, Y16(Orifici 2003) .

Estas avenidas que han afectado la región durante una época en la que Cahuachi estaba en plena evolución no determinaron el abandono ni el declive del sitio, si no solamente refacciones y remodelaciones de las estructuras. Los eventos climáticos no parecen ser la única causa del colapso del sitio. Su abandono debe estar igualmente vinculado con la emergencia de nuevos centros de poder en las zonas medias del valle de Nazca, Taruga y Las Trancas, donde serian progresivamente construidos los canales de irrigación subterráneos (Katharina Schreiber, Josué Lancho Rojas, 2003). Paralelamente, otros antiguos sitios situados en la misma región afectada por la degradación climática siguieron funcionando o tomando una mayor importancia. Aparentemente, es el caso de Estaqueria y de Usaca en el valle de Nazca (Orefici y Pieri, 1990, Isla, 1992) y La Muña en el valle de Palpa (Reindel e Isla, 2001). 
Alrededor del los 400-450 d.C se inicia el declive de Cahuachi. Las estructuras son sepultadas por rellenos generalmente compuestos de terrones y fragmentos de adobes y sobre ellos, en algunos casos, se aplico un sello de barro ${ }^{25}$. Los efectos de lluvias torrenciales posteriores al abandono de Cahuachi - alrededor de 1000 d.C.-, aportaron materiales de arrastre (barro y cantos rodados), que cubrieron el sitio, dañando en varias partes las capas de sello de barro y en otros casos algunos de los edificios enterrados. No obstante, la ausencia de esta capa de sello de barro en ciertos sectores, crean dudas sobre su aplicación al conjunto total de los monumentos enterrados.

El abandono y el enterramiento de los templos de Cahuachi generaron la movilización de grandes trabajos. Durante este contexto, diversos rituales y colocación de ofrendas fueron efectuados. Entre ellos destacan los sacrificios humanos y de animales, así como cantidades de recipientes e instrumentos de música en cerámica. Las 64 llamas sacrificadas descubiertas en el sector Y 13 (Orefici, 1994), muchas de ellas portaban collares con pendientes de hueso humano, otras tenían el pecho adornado con cintas de textil. Estos camélidos se encontraban asociados a dos cabezas trofeo, e igualmente a dos personas sacrificadas colocadas dentro de fosas circulares en posición sentada con las rodillas hacia el tórax. Al final del rito, una escultura lítica representando una cabeza trofeo $(25 \times 13 \times 15 \mathrm{~cm}$.), fue colocada sobre el apisonado construido sobre el relleno que enterraba a las llamas (Orefici, 2003 : 164, fig. 49). En el montículo 1 (Y1), antes de la clausura de los pasajes y de las escaleras de la ultima plataforma, un rito de rompimiento de antaras se efectuó in-situ. Los restos de estos instrumentos han sido precisamente descubiertos en los dos accesos en $\mathrm{L}$ de la plataforma (Bachir Bacha y Llanos, 2006).
Podemos señalar otro fenómeno observado a través de los diferentes sectores excavados: se trata de una serie de fogones dispuestos directamente debajo de la capa superficial. Esta práctica puede estar relacionada con el rito de destrucción y desmantelamiento de algunos edificios, efectuado al momento del abandono del sitio.

Las estructuras ceremoniales ritualmente selladas ofrecen una fisonomía de colinas, como si el objetivo haya sido regresar al aspecto original y natural del paisaje de Cahuachi. Esto sugiere que el sitio no perdió totalmente su prestigio religioso y quedó como un territorio sagrado funcionando como huaca. Posteriormente, el área se convirtió en una necrópolis cumpliendo el rol de pacarina; un lugar de origen mítico y nacimiento de una población que comparte la misma tradición y a donde retornan los hombres al morir. El descubrimiento de tumbas correspondiente a la época Nasca medio, tardío y de la época Huari son un testimonio de esta función.

\section{Cahuachi, centro ceremonial y lugar de poder}

Del examen de la evolución del sitio a través de sus contextos arqueológicos se desprende un cierto número de datos relativos a su función, su uso y sus ocupantes. Estos elementos modifican ciertas interpretaciones anteriores. Tratando de deducir cuales son las implicaciones de estos nuevos datos sobre la comprensión de la sociedad Nasca, podemos avanzar las propuestas siguientes:

La evolución arquitectónica de Cahuachi sugiere una evolución socio-política y refleja la imagen del poder a lo largo de los siglos. En un primer tiempo, los espacios abiertos que han podido favorecer la ejecución de ceremonias de contacto directo, parecen testigos de un poder naciente o en curso de consolidación. En un segundo tiempo, se configuran preferentemente espacios cerrados y restringidos, lo que estaría

\footnotetext{
${ }^{25}$ La capa de sello de barro empleada en Cahuachi, es una capa artificial compacta compuesta de arcilla, paja menuda y ripio. Ella cubre y cierra definitivamente las estructuras. Se la encuentra debajo de capa aluvial.
} 
indicando la institucionalización del poder. A la luz del análisis de las evidencias expuestas en este artículo se perfila la idea de una sede de poder tanto religioso como político, dotado de una estructura gobernante capaz de administrar, coordinar y perennizar grandes obras (pirámides, geoglifos). Este aparato político-religioso lograba movilizar en torno a él a todas las poblaciones de la cuenca del Río Grande y otras situadas mas allá de este territorio, como lo deja entrever la cultura material de varios sitios Nasca temprano.

Se observa que durante el periodo Nasca Temprano, desde Ica hasta Acarí, Cahuachi fue el único sitio ofreciendo una arquitectura monumental de gran envergadura. La repetición, a una escala menor, de su modelo arquitectónico ${ }^{26}$, las similitudes compartidas de un código icónico, de ritos funerarios y de artefactos observados en otros sitios de la cuenca del Río Grande, testimonian la existencia de una red de asentamientos secundarios y satélites, dirigidos por señores de menor rango. Estos últimos participaban en las festividades íntimas organizadas por los líderes de Cahuachi a quienes se les rendían tributo. Aunque de carácter administrativo y residencial, estos sitios no estuvieron desprovistos de funciones religiosas y su dependencia hacia Cahuachi no impedía fermentos de rivalidad frente a este centro. Algunos de ellos fueron abandonados al mismo tiempo que Cahuachi, como por ejemplo Los Molinos en Palpa (Reindel e Isla, 2001 : 311) y Tambo Viejo en Acarí (Menzel, 1971 : 64; Valdez, 2000 : 163) mientras que otros se mantuvieron y se desarrollaron.

Si bien, los datos disponibles sobre la sociedad Nasca no se limitan solamente a los materiales descubiertos en Cahuachi, comprender su función nos orienta hacia la definición de una organización social compleja de tipo estatal. A parte del carácter político dominante de Cahuachi, otros aspectos culturales van en el sentido de esta hipótesis: un sistema de comunicación simbólico institucionalizado a través de un código icónico, una jerarquía de establecimientos, el tratamiento funerario socialmente diferenciado, una gran producción de objetos suntuarios y la existencia de un comercio de objetos exóticos o de lujo (obsidiana, spondylus, plumas).

Lo que asienta el poder de Cahuachi es su función política-religiosa. Así se explica la constante ambivalencia de todas las actividades observadas durante las excavaciones: lo sagrado se mezcla con lo profano, lo ceremonial penetra lo residencial, lugares rituales y lugares de producción vienen a entrelazarse. La fabricación de cerámica y de textiles fue el soporte de un código icónico instaurado por la elite dirigente. La producción agrícola estuvo ritmada por los cultos dedicados al agua y a los ancestros como testimonia la iconografía. Lo que legitima el poder de Cahuachi es la renovación de los templos, condicionando la ejecución de ofrendas y ceremonias complejas que incluyen sacrificios humanos.

Todos estos elementos instalan una diferencia con respecto al modelo de las jefaturas "atomizadas" propuesto por algunos autores. Sin embargo, la naturaleza profunda de este Estado andino es aún materia de reflexión. Trabajos futuros abordando el espacio de poder de Cahuachi, la organización territorial Nasca, así como la simbología y la iconografía de esta cultura ayudaran a comprender este aspecto.

\section{Agradecimientos}

Agradezco al director del CISRAP Giuseppe Orefici su disposición para publicar datos de

\footnotetext{
${ }^{26}$ Los sitios mejor documentados y recientemente excavados ofreciendo una arquitectura parecida a Cahuachi pero de escala menor son Los Molinos en el valle de Palpa (Reindel y Isla, 2001) y Estaqueria en el valle de Nasca (Orefici y al. 1998, 1999).
} 
campo y por haberme permitido la consultación de los archivos del CISRAP; a la doctora Elvina Pieri por su apoyo en la consulta de los mismos y a los arqueólogos y Oscar Llanos Luisa Díaz Arriola por la corrección del estilo del texto.

\section{Bibliografía}

Acosta, José de

1962 [1590] Historia natural y moral de las Indias. México : Fondo de cultura económica.

Bachir Bacha, Aïcha

2006 "Del ser mítico al guerrero. Iconografía y arqueología de la cabeza trofeo Nasca", ponencia presentada en el $52^{\circ}$ Congreso Internacional de Americanistas, Universidad de Sevilla, 20 de julio.

Bachir Bacha, Aïcha \& Oscar LLANOS

2006 "El Gran Templo del centro ceremonial de Cahuachi, Nazca, Perú”. Dimensión antropológica 38 en prensa.

Eeckhout, Peter

1998 "Pirámide con rampa n III, Pachacamac, nuevos datos, nuevas perspectivas". Bulletin de l'Institut Français d'Etudes Andines, tomo 28 (1): 169-214.

1999 "Le temple de Pachacamac sous l'empire Inca". Journal de la Société des Américanistes, tomo 84 (1) : 9-44.

Grodzicki, Jerzy

1991 "Nasca : Los síntomas geológicos del fenómeno el Niño y sus aspectos arqueológicos." Varsovia : Coll. Estudios y memorias 12, CESLA, Universidad de Varsovia.

Isla Cuadrado, Johny

1990 "La Esmeralda : una ocupación del periodo arcaico en Cahuachi”. Gaceta arqueológica andina 20: 67-80, Lima.

Isla Cuadrado, Johny

1992 "La ocupación nasca en Usaca". Gaceta Arqueológica Andina 22: 119-151.

Kroeber Alfred \& Donald Collier

1998 The Archaeology and Pottery of Nazca, Peru. Alfred L. Kroeber's 1926 Expedition, edición de Patrick $\mathrm{H}$.
Carmichael. Walnut Creek : Alta Mira Press.

Lavalle José Antonio de

1986 Nazca, colección arte y tesoros del Perú. Banco de Crédito del Perú, Lima.

Menzel Dorothy

1971 "Estudios arqueológicos en los Valles de Ica, Pisco, Chincha y Cañete". Arqueología y Sociedad 6, Lima.

Onuki Yoshio

1993 Las actividades ceremoniales tempranas en la Cuenca del Alto Huallaga y Algunos problemas generales. En El Mundo Ceremonial Andino, editado por Luís Millones \& Yoshio Onuki, Coll. Senri Ethnological Studies 37 : 69-96. Osaka : Museo nacional de etnología.

\section{Orefici Giuseppe}

1989 Una expresión de arquitectura monumental Paracas-Nasca : El Templo del Escalonado. Atti del Convengo Internazionale "Archeologia, Scienza e Societa nell America Precolombiana", Brescia 1988, pp. 191-201. Brescia : CISRAP.

1993 Nasca: arte e societá del popolo dei geoglifi. Milan : Jaca Book.

1994 2El recinto de los camélidos". Documentos de Trabajo 15-4Memorias del VI Congreso de la FIEALC (Varsovia, 23-26 de Junio de 1993), pp. 49-53. Varsovia : CESLAUniversidad de Varsovia.

1996 "Nuevos enfoques sobre la transición Paracas - Nasca en Cahuachi”. Andes Boletín de la Misión Arqueológica Andina 1:173-198. Varsovia

Orefici, Giuseppe \& Elvina Pieri

1987- 1997 Proyecto Nasca 1982-1996, informes finales de las campañas de 1987 a 1996, dactilografiados presentados al INC. Lima: CISRAP.

Orefici, Giuseppe, Elvina Pieri \& Angel Sanchez 1998 - 1999 Proyecto Nasca 1997-2001, informes finales de las campañas de 1997 y 1998, 
dactilografiados presentados al INC. Lima: CISRAP.

Orefici, Guiseppe \& Andrea Drusini

2003 Nasca. Hipótesis y evidencias de su desarrollo cultural. Lima: CISRAP.

Proulx, Donald A

1968 Local differences and time differences in Nasca Pottery. University of California Publications in Anthropology, vol. 5.

Reindel, Markus \& Johny Isla Cuadrado

2001 Los Molinos y la Muña. Dos centros administrativos de la cultura Nasca en Palpa, costa sur del Perú. Beiträge zur Allgemeinen und Vergleichenden Archäologie, $21: 289$-317. Mainz.

Reinhard Johan

1997 Las líneas de Nazca. Un nuevo enfoque sobre su origen y significado. Editorial Gráfica Pacific Press S.A., Lima.

\section{Rossel Castro Alberto}

1977 Arqueología sur del Perú. Editorial Universo S.A., Lima.

Rowe, John H.

1963 Urban settlements in ancient Peru. Nawpa Pacha, vol. 1:1-27. Berkeley, California,

Sawyer Alan R

1997 Early Nasca needlework. London: Laurence King Publishing.

Schreiber Katharina \& Josué Lancho Rojas

2003 Irrigation and society in the peruvian desert. The Puquios of Nasca. Oxford: Lexington Books.

Shimada Izumi, Carlos Elera \& Melody Shimada

1982 Excavaciones efectuadas en el centro ceremonial de Huaca Lucia-Cholope del Horizonte Temprano, Batan Grande, costa norte del Perú. Arqueológicas 19: 109-210.

Silverman Helaine

1985 "Cahuachi : simplemente monumental". Boletín de Lima 41: 8595. Lima.

Silverman Helaine

1986 "La investigación arqueológica y el uso de la analogía etnográfica". Revista Andina 2: 465-478. Cusco.

Silverman, Helaine

1993 Cahuachi in the Ancient Nasca World. Iowa City: University of Iowa Press.

Strong, William D.

1957 Paracas, Nazca and Tiahuanacoid Cultural Relationships in South Coastal Peru. Memoir 13, Society for American Archaeology. Salt Lake City.

Tello, Julio César

1959 Paracas. Primera parte. Empresa gráfica T. Scheuch S.A. Lima.

Valdez, Lidio

2000 "La tradición cultural de Huarato de Acarí y sus relaciones con Nasca". Arqueología y Sociedad 13 : 159-171. UNMSM, Lima.

Ziólkowski, Mariusz S. et Al.

1994 Andes Radiocarbon Database for Bolivia, Ecuador and Peru. Gliwice : Andean Archaeological Mission \& Gliwice Radiocarbon Laboratory. 